\title{
Vertebroplasty and Kyphoplasty: A Systematic Review of 69 Clinical Studies
}

\author{
Paul A. Hulme, MSc, ${ }^{*}$ Jörg Krebs, DVM, ${ }^{*}$ Stephen J. Ferguson, PhD, ${ }^{*}$ and \\ Ulrich Berlemann, MD†
}

Study Design. Systematic literature review.

Objective. To evaluate the safety and efficacy of vertebroplasty and kyphoplasty using the data presented in published clinical studies, with respect to patient pain relief, restoration of mobility and vertebral body height, complication rate, and incidence of new adjacent vertebral fractures.

Summary of Background Data. Vertebroplasty and kyphoplasty have been gaining popularity for treating vertebral fractures. Current reviews provide an overview of the procedures but are not comprehensive and tend to rely heavily on personal experience. This article aimed to compile all available data and evaluate the clinical outcome of the 2 procedures.

Methods. This is a systematic review of all the available data presented in peer-reviewed published clinical trials. The methodological quality of included studies was evaluated, and data were collected targeting specific standard measurements. Where possible, a quantitative aggregation of the data was performed.

Results. A large proportion of subjects had some pain relief, including $87 \%$ with vertebroplasty and $92 \%$ with kyphoplasty. Vertebral height restoration was possible using kyphoplasty (average $6.6^{\circ}$ ) and for a subset of patients using vertebroplasty (average $6.6^{\circ}$ ). Cement leaks occurred for $41 \%$ and $9 \%$ of treated vertebrae for vertebroplasty and kyphoplasty, respectively. New fractures of adjacent vertebrae occurred for both procedures at rates that are higher than the general osteoporotic population but approximately equivalent to the general osteoporotic population that had a previous vertebral fracture.

Conclusions. The problem with stating definitely that vertebroplasty and kyphoplasty are safe and effective procedures is the lack of comparative, blinded, randomized clinical trials. Standardized evaluative methods should be adopted.

Key words: osteoporotic, vertebral fracture, vertebroplasty, kyphoplasty. Spine 2006;31:1983-2001

Osteoporosis is estimated to afflict 200 million women worldwide. ${ }^{1}$ A total of 1.5 million new fractures, nearly half of which are vertebral $(700,000)$, are reported in the

From the *M.E. Müller Institute for Surgical Technology and Biomechanics, Bern, and †Spine Center, Thun, Switzerland.

Acknowledgment date: February 16, 2005. First revision date: July 15, 2005. Second revision date: October 14, 2005. Acceptance date: October $19,2005$.

The device(s)/drug(s) is/are FDA-approved or approved by corresponding national agency for this indication.

Foundation funds were received in support of this work. No benefits in any form have been or will be received from a commercial party related directly or indirectly to the subject of this manuscript.

Address correspondence and reprint requests to Paul A. Hulme, MSc, Research Center for Orthopaedic Surgery, Institute for Surgical Technology and Biomechanics, University of Bern, Stauffacherstr. 78, 3014 Bern, Switzerland; E-mail: Paul.Hulme@MEMcenter.unibe.ch
United States each year, outnumbering fractures of the hip and ankle combined. ${ }^{2-5}$ Vertebral fracture may result in pain about the fracture site, loss of height caused by vertebral collapse, spinal instability, and, in many cases, kyphotic deformity. ${ }^{6}$ Although some patients respond to the conservative treatment of medications, bracing, and bed rest, many do not. Chronic pain and kyphotic deformity may lead to depression, decreased appetite (leading to poor nutrition), decreased pulmonary function, impaired mobility, and a reduction in the quality of life, the ultimate result being a significant increase in morbidity. ${ }^{7-11}$ To relieve chronic pain, bed rest is often the only solution. However, this solution can result in a vicious cycle of increased bone loss caused by inactivity and, correspondingly, increased vertebral fracture risk. ${ }^{8}$ Thus, interest has been fostered in percutaneous cement injection methods for fracture stabilization that reduce or eliminate pain, allowing a return to normal activity in a short period of time.

Galibert et $\mathrm{al}^{12}$ first reported vertebroplasty in 1987 for the minimally invasive treatment of hemangiomas, which, since then, has been adapted for use in the treatment of intractable, focal, intense pain localized to a vertebral fracture. Kyphoplasty was introduced in 1998 to restore vertebral body height and help realign the spine, using an inflatable balloon to reduce the fracture before the injection of cement. ${ }^{8,13}$ Currently, vertebroplasty and kyphoplasty have been gaining popularity to stabilize vertebral fractures mainly caused by osteoporosis but also including malignant involvement of the spinal column, hemangioma, and vertebral osteonecrosis. ${ }^{14}$ There is a need for critical evaluation of the supporting evidence to provide, where possible, a quantitative aggregation of the safety and efficacy of the procedures. A number of reviews of the 2 procedures currently exist. ${ }^{3,13,15-21}$ Although they provide an excellent overview of the procedures, they are not comprehensive and tend to rely heavily on personal experience rather than objective assessment. This article will compile the available data presented in peer-reviewed published clinical studies to address the following questions:

1. Does vertebroplasty/kyphoplasty reduce patient pain? How does this compare to conservative treatment? Is pain reduction durable over the longterm?

2. Does vertebroplasty/kyphoplasty restore patient function?

3. Does vertebroplasty/kyphoplasty restore the normal spinal alignment? 
4. What are the complications associated with the procedures?

5. Does the incidence of augmented or adjacent vertebral fracture increase after vertebroplasty/kyphoplasty?

6. Does kyphoplasty offer a significant improvement in terms of restoration of spinal alignment, pain management, and reduction in cement leakage over traditional vertebroplasty?

\section{- Materials and Methods}

To our knowledge, there are no published reports of randomized clinical trials for either vertebroplasty or kyphoplasty, therefore, the search was extended to include nonrandomized clinical trials. ${ }^{22}$ No restrictions were placed on the age or gender of the subjects, or the duration, localization, and type of symptoms experienced.

Search Strategy. MEDLINE, Cochrane Library, and ISI Current Contents were searched. No restrictions were placed on language, publication date, or publication type for the initial searches within these databases. Searches were performed in June and November 2004 and repeated in June 2005. For the initial search, the terms "vertebroplasty" and "kyphoplasty" were used because they have been established terms from the inception of the techniques. Specific key words were used to focus the search results on clinical studies, further refined by manual inspection of the abstracts. Articles were excluded from further analysis for reporting no clinical outcomes (i.e., article was a review, editorial, technical, or animal study), involving techniques other than vertebroplasty/kyphoplasty, or if the study was published in a language other than English, German, French, or Spanish. To reduce potential confounding factors, included studies were limited to subject populations that had more than $80 \%$ primary or secondary osteoporotic vertebral compression fractures and procedures that used polymethyl methacrylate cement. We tested our search strategy by ensuring that our search results included all the studies identified by previous reviews. ${ }^{3,13,20,23}$

Methodological Evaluation. To date, a standardized method for the evaluation of nonrandomized studies has not been formalized. We used a modified version of the methodological quality assessment proposed by Downs and Black ${ }^{24}$ and later modified by MacLehose $\mathrm{et} \mathrm{al},{ }^{25}$ and included recommendations of other investigators (Table 1). ${ }^{26,31}$ It contains all the elements recommended by the Agency for Healthcare Research and Quality, Cochrane Collaboration Back Review Group, NSW Department of Health, NHS R\&D Health Technology Assessment Programme, and the Ottawa Health Research Institute. ${ }^{28,30-32}$ Questions were grouped into the categories: reporting; external validity; internal validity, including bias and confounding; and power (Table 1). Internal validity refers to systematic errors of biases or confounding factors inherent in the study design. External validity refers to how the results provide a correct basis for generalization to other circumstances. ${ }^{33}$ At least 2 reviewers reviewed articles. Reviewers gave each element a score of 1 (yes) or 0 (no, unclear). We aimed for consensus, but if necessary, a third reviewer was consulted.

Data Collection. Data were collected for each study under the headings "general information," "participants," "interven- tion," "outcomes," "complications," and "follow-up." General information included the type of intervention, pathology, and type of study. Participant information was comprised of the age and gender of the subjects, description of symptoms, and drop out during follow-up. Cement type, injected amounts, approach, number of sessions, number of vertebra per session, levels augmented, usage of fluoroscopy, computerized tomography (CT), and venography were all noted under the heading "intervention." Outcome data were collected detailing pain relief, general health, functional improvements, satisfaction with treatment, and reduction in kyphosis. Complications included cement leakage (asymptomatic and symptomatic), neurologic deficits, cardiovascular, pulmonary, and any other clinically relevant complication. Long-term follow-up information was comprised of all the items recorded under the heading "outcome," with the addition of new fracture details. It is noteworthy that studies that did not explicitly state whether cement leakage, complications, or new fractures did or did not occur were not included in totals used to calculate the proportion of subjects/vertebrae that were affected.

Statistics. Statistics were kept to a descriptive level. Comparative data (i.e., differences in VAS) are reported as the difference between the means $\pm 95 \%$ confidence level calculated from the standard error of the difference between 2 sample means. Binomial proportional data are expressed as the proportion \pm $95 \%$ confidence level calculated from the standard error using the normal approximation. The combined mean across multiple studies was weighted according to the number of subjects and is expressed as the combined mean \pm the combined $95 \%$ confidence level (calculated from the within study variance).

\section{- Results}

\section{Methodological Analysis}

The majority of articles reviewed were retrospective in nature, including 37 retrospective, 25 prospective, and 7 study design not reported. The evaluated articles were of varying methodological quality. Mean quality score was $17.6 \pm 3.7$ standard deviation (SD) (range 9-23.5) of a maximum of 29. The summary of the methodological score for each question is provided in Figure 1. Although descriptive parameters were often reported (question Nos. 1-4, and 9), no study was randomized, and only a few studies had an aspect of the study that was blinded (question Nos. 16 and 26). ${ }^{34-39}$ While not specifically targeted in the methodological quality assessment, it was noted that very few studies included a control group. ${ }^{40,41}$ Items that were not consistently reported were confounding factors, bias and limitations (question Nos. 5, 7, 24, and 27).

On the whole, the main findings were not clearly described (question No. 4), and results were presented without information on their variability (question No. 8). Follow-up times were assessed with respect to the aim of the study. Remarkably, those studies whose aims were to assess the pain relief and occurrence of new fractures after vertebroplasty and kyphoplasty often had short or no follow-up times (question No. 19). No studies were excluded on the basis of methodological quality because removing articles that scored in the bottom $50 \%$ had little effect on outcomes. 
Table 1. Methodological Quality Assessment Questions

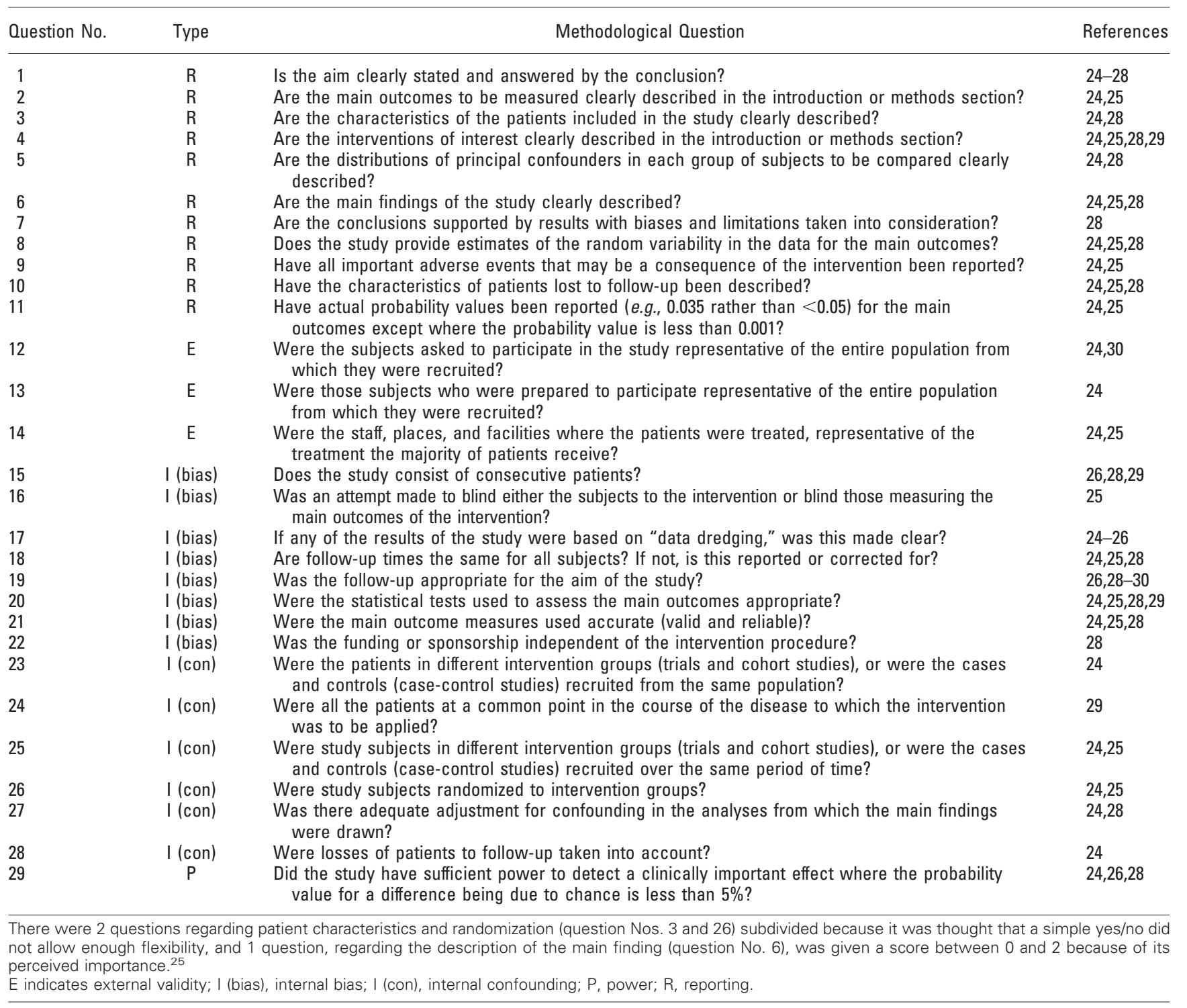

\section{Clinical Details}

Studies providing the data for this review are referenced in Table 2. Vertebroplasty studies (12 prospective, 29 retrospective, and 6 unreported) showed the results of 2958 subjects ( $\mathrm{n}=47$ studies), including 1959 females, 676 males, and 323 unreported with a mean age of 72 years (mean range $59-79, \mathrm{n}=45$ studies), who underwent 4456 procedures. Kyphoplasty studies (13 prospective, 8 retrospective, and 1 unreported) showed the results of 1288 subjects ( $\mathrm{n}=22$ studies), including 829 females, 403 males, and 56 unreported with a mean age of 72 years (mean range 67.5$75, \mathrm{n}=20$ studies), who underwent 1624 procedures. Of vertebroplasty and kyphoplasty procedures, $50 \%$ and $60 \%$, respectively, were performed within the thoracolumbar region of the spine (T11-L2 inclusive).

\section{Pain}

As shown in Figure 2, a large proportion of subjects had some pain relief independent of the type of procedure: vertebroplasty $87 \%(\mathrm{n}=1552,32$ studies, $95 \%$ confi- dence interval [CI] $78 \%$ to $95 \%$ ); and kyphoplasty $92 \%$ ( $\mathrm{n}=447,7$ studies, $95 \%$ CI $86 \%$ to $98 \%$ ). Visual analog pain scores (VAS) (normalized to 10-point scale) were reduced from an average of $8.2(\mathrm{n}=666,12$ studies, $95 \%$ CI $7.8-8.6)$ and $7.15(\mathrm{n}=183,4$ studies, $95 \% \mathrm{CI}$ 6.6-7.7) to 3.0 (95\% CI 2.4-3.6) and 3.4 (95\% CI 2.74.1) for vertebroplasty and kyphoplasty, respectively (Figure 3). There were 2 studies that showed SF-36 scores for kyphoplasty. ${ }^{8,97}$ Body pain scores increased between 22.4 and 47.1 points, while the physical function scores decreased between 17.2 and 29.3 points. The only items that did not have any statistically significant improvement were general health, role emotional, and mental health.

\section{Physical Function}

A $16 \%$ to $47 \%$ full-scale improvement in physical function was reported after vertebroplasty for 7 studies using different variants of a 5-point mobility scale. ${ }^{10,36,61-64,91}$ Between $49 \%$ and $90 \%$ of subjects reported ambulation 


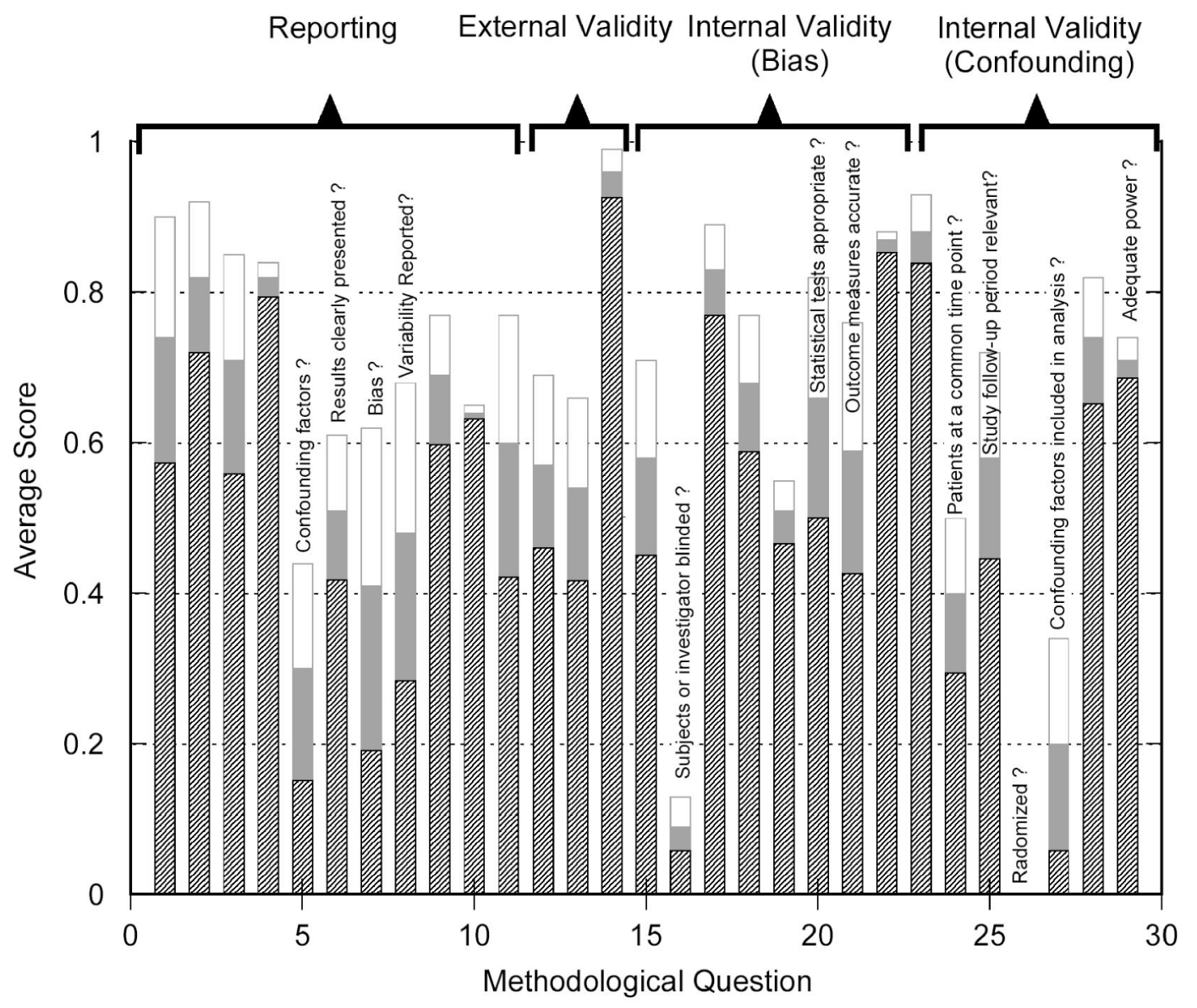

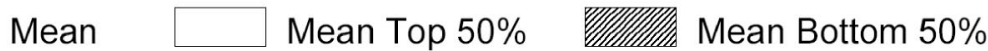

Figure 1. Methodological quality assessment score. Randomized trials were not available, and blinded trials were infrequent. The bars represent the average score for all kyphoplasty and vertebroplasty articles reviewed.

improvements in 4 studies assessed by qualitative patient response. ${ }^{14,34,35,65}$ There were 3 studies that showed improvements in physical function using a validated health-related outcome instrument: Nottingham
Health Profile $\mathrm{e}^{42,43}$ and Oswestry Disability Index (ODI) (preoperative $61 \%$, postoperative $46 \%, \mathrm{n}=23 \mathrm{sub}-$ jects). ${ }^{44}$ Two kyphoplasty studies showed improvements in disability (mean ODI preoperative $60 \%$, postopera-

Table 2. References for Clinical Details

\begin{tabular}{|c|c|c|}
\hline Clinical Details & Vertebroplasty Studies Referenced & Kyphoplasty Studies Referenced \\
\hline \multicolumn{3}{|l|}{ Study design } \\
\hline Prospective & $4,14,39,40,42-50$ & $8,41,44,51-60$ \\
\hline Retrospective & $10,17,34-38,61-82$ & 83-90 \\
\hline Not Reported & $91-96$ & 97 \\
\hline \multicolumn{3}{|l|}{ Pain relief } \\
\hline Subjects with some pain relief (\%) & $17,34-37,42,43,46,47,49,50,61,62,65,66,68-70,72,73,75-81,91,92,94,95,98$ & $8,41,44,51,52,55-60,83,84,87-89,97,99$ \\
\hline Pain relief VAS & $4,10,36,40,42-44,46-49,61-64,66,70,75,79,80,91,100$ & $8,44,51-53,55,58,83,88,89,99$ \\
\hline Mobility & $10,14,34-36,43,44,48,50,61-65,73,91,101$ & 44,51 \\
\hline \multicolumn{3}{|l|}{ Height restoration } \\
\hline Height & $39,44,45,66,67,76,82,93,96$ & $41,44,51,53,56,59,83,84,88,89,97$ \\
\hline Correction of kyphosis & $39,44,45,66,67,76,82,92,93$ & $41,44,51-55,83,84,87$ \\
\hline $\begin{array}{l}\text { Subjects with no increase in height or } \\
\text { reduction in kyphosis angle }(\%)\end{array}$ & $39,44,45,66,67,82,92,93,96$ & $41,44,51-53,89,97,99$ \\
\hline \multicolumn{3}{|l|}{ Complications } \\
\hline Leakage & $4,17,34,36,37,39,42-50,66-70,72,74-78,80,91,92,95,101,102$ & $8,41,44,51,52,54-60,83,84,87-89,97$, \\
\hline Leakage location & $4,14,17,34,36,37,39,42-50,66,68-70,72,74-78,80,91,92,95,101,102$, & $8,51,52,55,56,58,60,83,97,99$ \\
\hline Procedural versus cement complications & $4,10,14,17,34,36,37,40,42,49,50,63,68,69,70,74,75,101$ & $8,41,51,54-57,87,88,97$ \\
\hline Serious complications reported & $4,10,14,17,34,36,37,39,40,42-45,47-50,61,63,65-70,74-78,80,92,95,101$ & $8,41,51,52,54-57,59,83,84,87-89,97$ \\
\hline New fractures & $4,34,40,42,44,46-49,65,68-71,75,95,101$ & $41,51,52,54,56-58,83-86,88$ \\
\hline
\end{tabular}




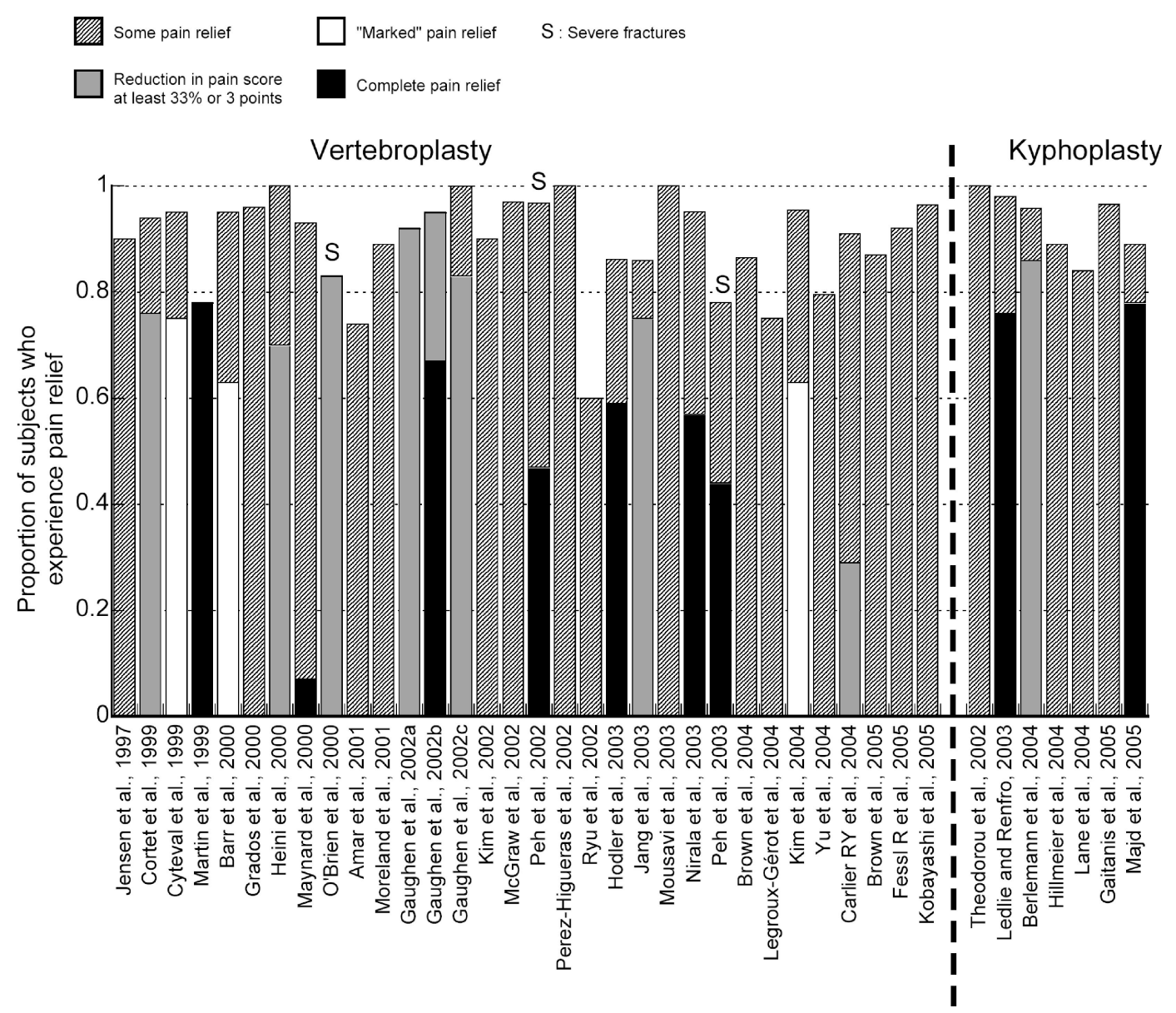

Figure 2. Proportion of subjects who undergo vertebroplasty and kyphoplasty, and have pain relief. Pain relief is illustrated for 4 different methods in which it was reported. "Some pain relief" includes all patients who had a reduction in pain, regardless of the magnitude. Studies that used the descriptor "Marked Pain Relief" did not indicate the magnitude of pain relief experienced. The other 2 methods are self explanatory. Severe fracture is defined as a loss of vertebral height more than $67 \%$ of its original height.

tive $32 \%, \mathrm{n}=77$ subjects). ${ }^{44,51}$ Reporting improvements in physical function appears to be of secondary importance to the investigators, therefore, measurement scales used are inconsistent, thus scores cannot be pooled.

\section{Kyphosis/Vertebral Height Correction}

A qualitative examination of the data presented in Tables 3 and 4 appears to indicate that vertebral height restoration is similar for either procedure, provided a mobile fracture or intravertebral cleft is present. However, few studies considered measurement precision or corrected for magnification error between radiographs (Tables 3, 4). Interstudy comparisons are further complicated by the use of different methods for percentage height restoration and reduction of kyphosis angle calculation. ${ }^{45}$ Mean kyphotic angle restoration was $6.6^{\circ}$ $\left(\mathrm{n}=335,4 \text { studies, range } 5.0^{\circ}-8.4^{\circ}\right)^{66,67,92,93}$ and $6.6^{\circ}$ $\left(\mathrm{n}=505,9 \text { studies, range } 3.4^{\circ}-9.9^{\circ}\right)^{51,52-55,83,84,103}$ for vertebroplasty and kyphoplasty, respectively. Not all subjects had a reduction in kyphotic angle or restoration of height (less than $5^{\circ}$ change in kyphotic angle or an increase in height as defined by the investigator). A mean of $34 \%$ ( $\mathrm{n}=404,9$ studies, $95 \%$ CI $22 \%$ to $46 \%$ ) and $39 \%$ ( $\mathrm{n}=512,8$ studies, $95 \%$ CI $28 \%$ to $50 \%$ ) of kyphoplasty and vertebroplasty interventions, respectively, did not result in an appreciable restoration of height or kyphotic angle.

\section{Complications}

Immediate complications associated with vertebroplasty and kyphoplasty can be separated into 2 categories, procedural and cement leakage (ratio 5:14 kyphoplasty, 25:49 vertebroplasty). Reported procedural complications include infection, ${ }^{63,68,69}$ fractures of the transverse process, pedicle, sternum and ribs, ${ }^{10,14,37,40,63,94,97}$ and respiratory distress caused by the anesthetic. ${ }^{34,98} \mathrm{Ce}-$ ment leakage occurred in $41 \%(\mathrm{n}=2283$ vertebrae, 27 studies, $95 \%$ CI $32 \%$ to $50 \%$ ) of vertebrae during vertebroplasty and $9 \%(\mathrm{n}=1486$ vertebrae, 18 studies, $95 \%$ CI $2.6 \%$ to $15.8 \%$ ) of vertebrae during kyphoplasty (Figure 4).

It is noteworthy that mean leakage rate was calculated independent of the measurement method used and patient inclusion criteria. The distribution of leaks was $32 \%$ and $11 \%$ epidural, $32.5 \%$ and $48 \%$ paraspinal and $30.5 \%$ and $38 \%$ intradiscal, $1.7 \%$ and 1.5 pulmonary and $3.3 \%$ and 1.5 foraminal for vertebroplasty (1081 leakage locations reported, 30 studies) and kyphoplasty 


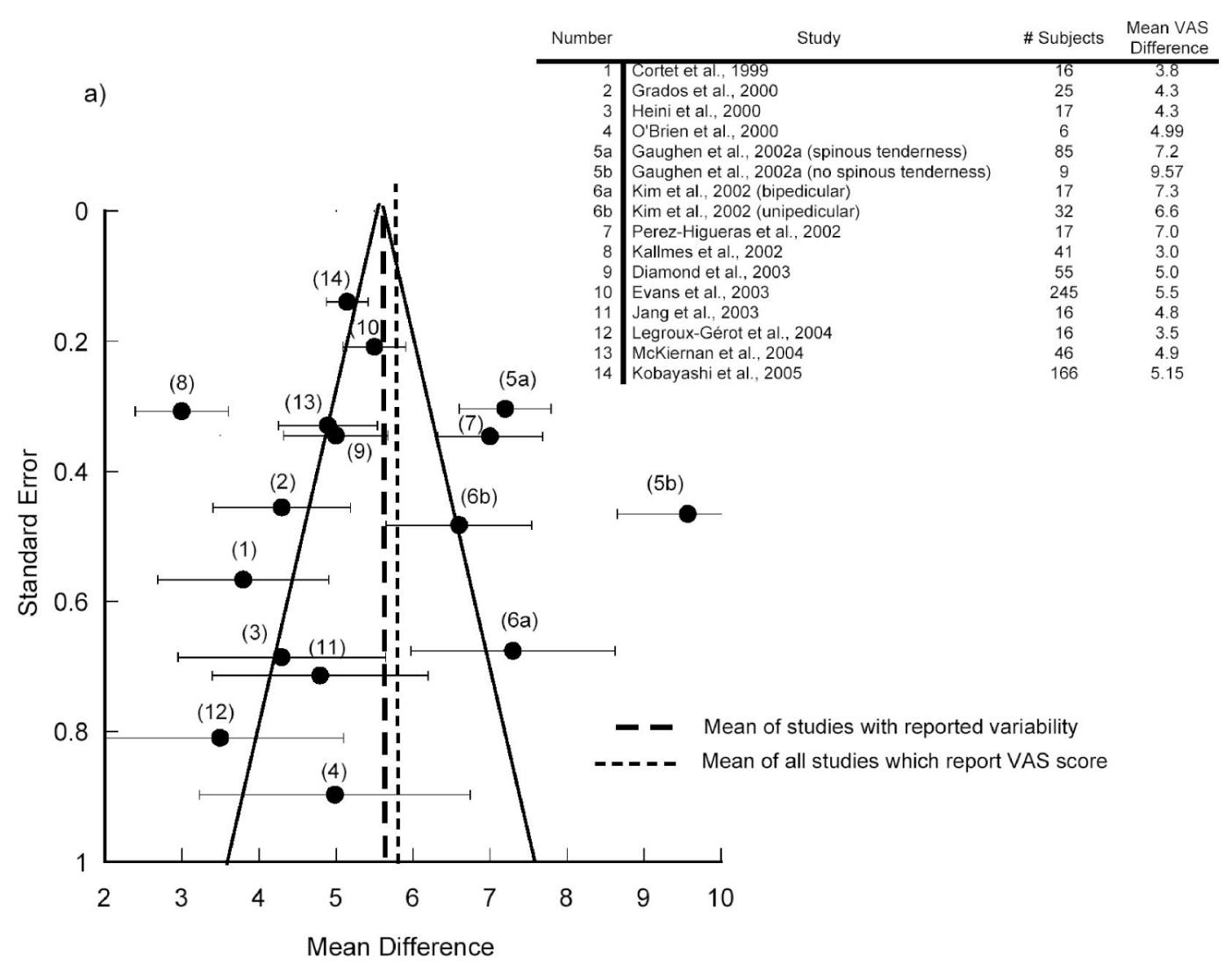

b)

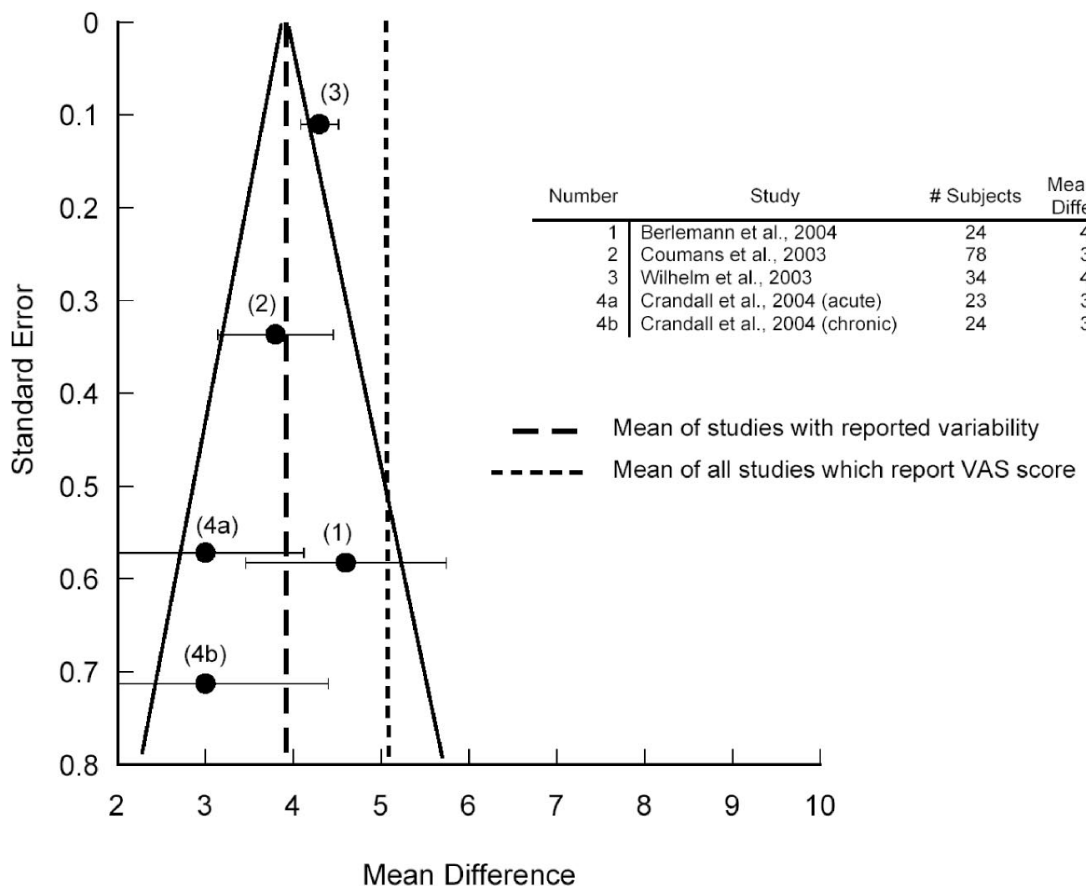

Figure 3. Funnel plots for vertebroplasty (A) and kyphoplasty (B) VAS difference scores between preoperative and postoperative values. Variability was not provided for all studies. Therefore, 2 means were constructed, one for studies in which variability was reported and another for all studies. The solid line indicates the region in which one would expect $95 \%$ of the data to lie within. The kyphoplasty plot shows a symmetrical inverted funnel, indicating a probable lack of publication bias. The same is not true for the vertebroplasty plot. Asymmetry could be caused by publication bias, inadequate methodological quality, or interstudy differences in subject inclusion criteria. VCF indicates vertebral compression fracture. 


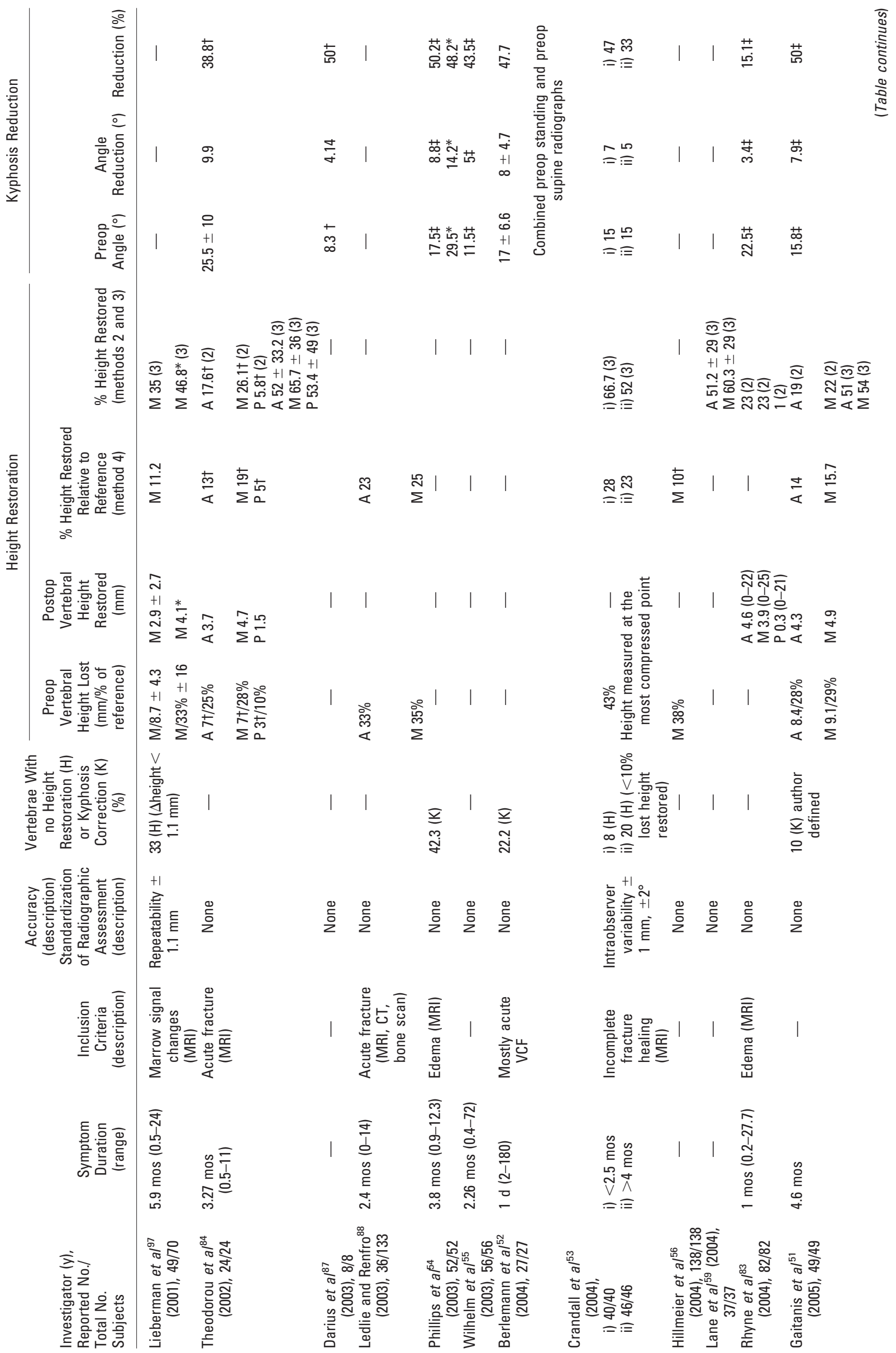

Copyright $($ Lippincott Williams \& Wilkins. Unauthorized reproduction of this article is prohibited. 


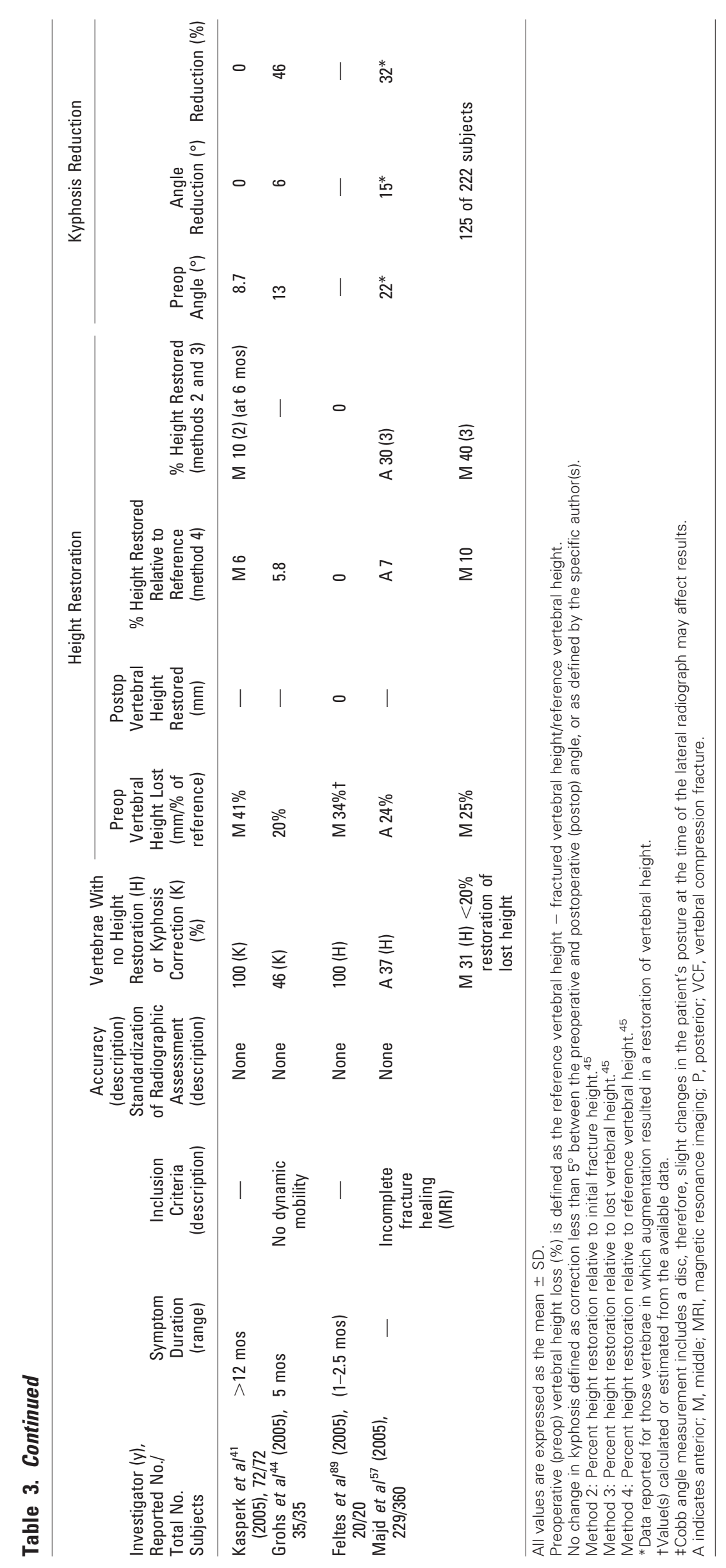

Copyright (c) Lippincott Williams \& Wilkins. Unauthorized reproduction of this article is prohibited. 


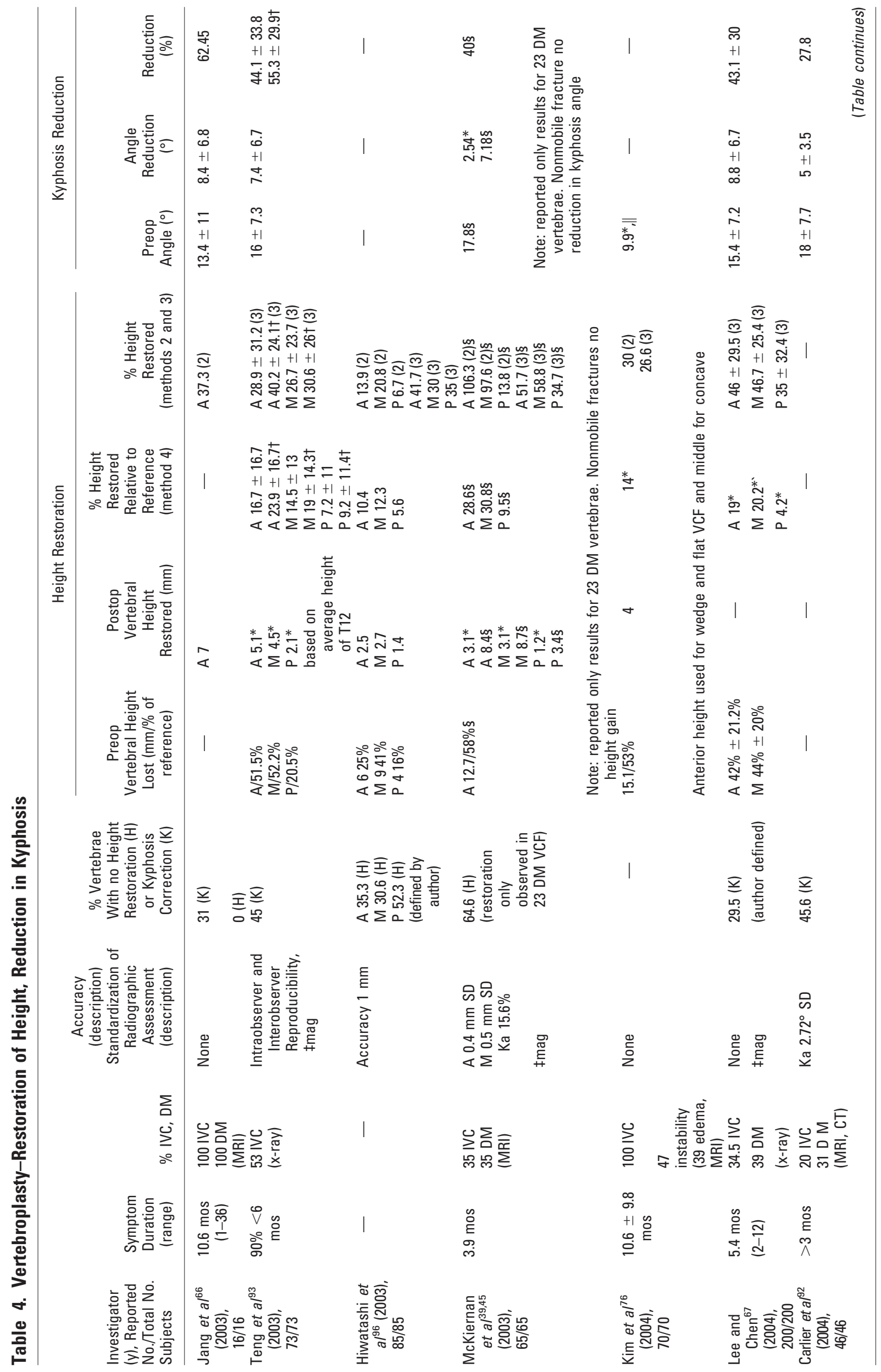

Copyright $\odot$ Lippincott Williams \& Wilkins. Unauthorized reproduction of this article is prohibited. 


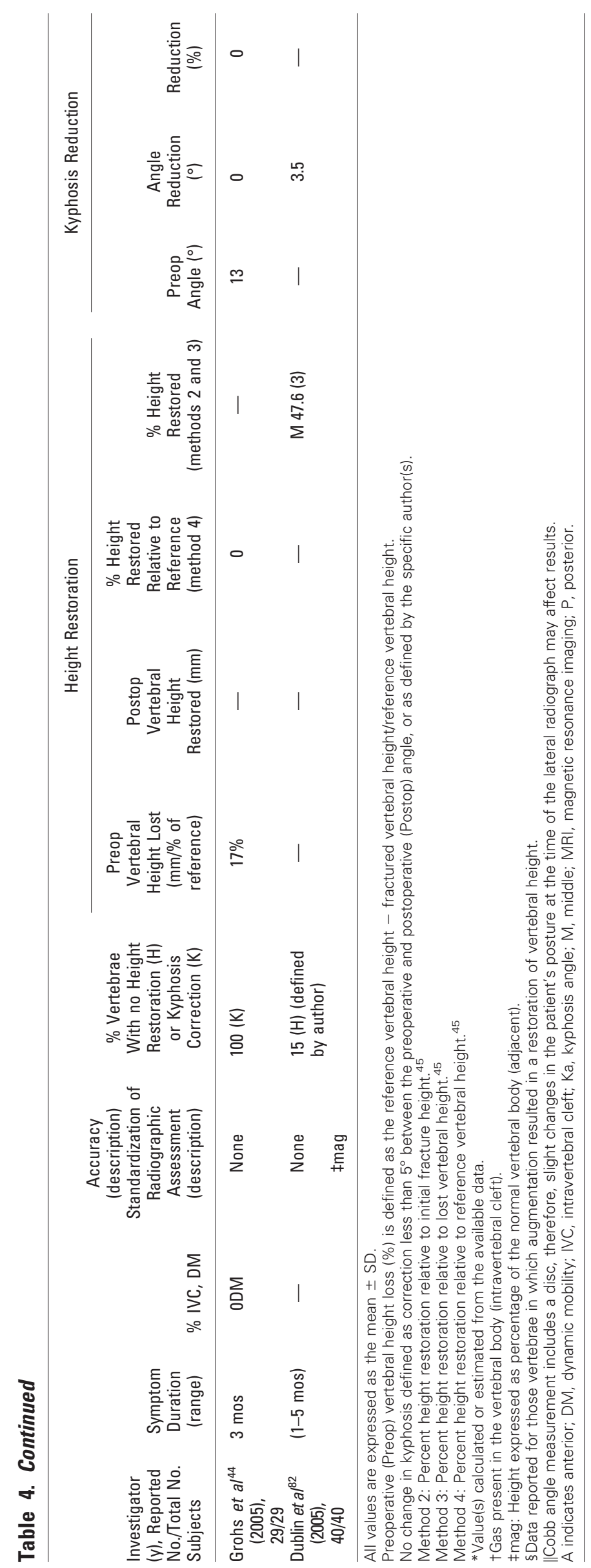

Copyright $($ Lippincott Williams \& Wilkins. Unauthorized reproduction of this article is prohibited. 


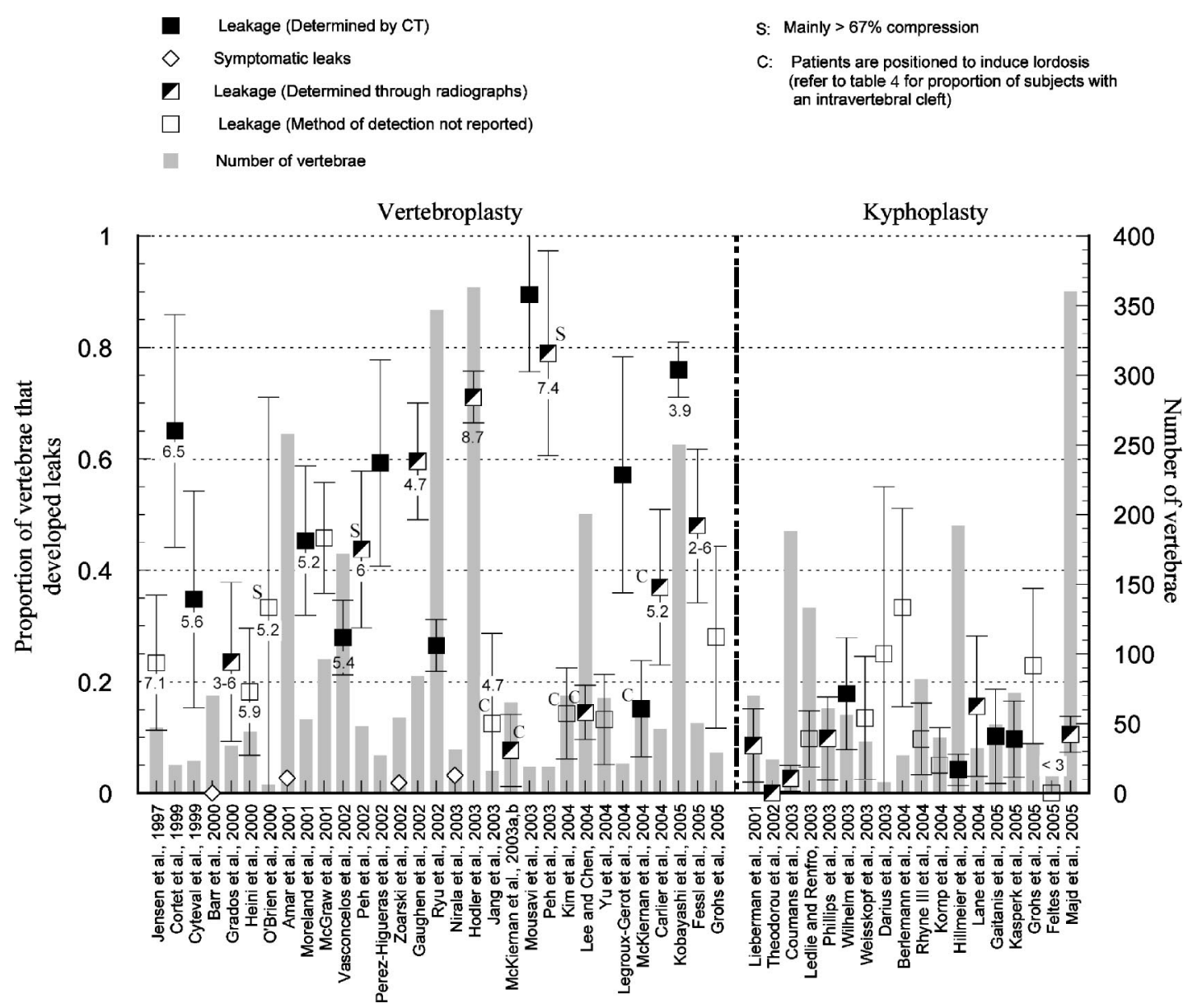

Figure 4. Proportion of vertebrae in which leaks developed during vertebroplasty and kyphoplasty. The body of evidence to date suggests a high degree of variability in leakage rates for vertebroplasty and kyphoplasty. Differing results may be caused by the amount of cement injected or percentage of the vertebra filled, level augmented, severity of the fracture, viscosity of the cement, injection pressure, leakage detection method used, and whether only clinically relevant leaks were reported. Leakage data are presented as the mean $\pm 95 \% \mathrm{Cl}$. Numbers given below the data points are the mean injected cement volumes $(\mathrm{mL})$.

(65 leakage locations reported, 10 studies), respectively. Most leaks were clinically asymptomatic. Clinical complications occurred for $2.6 \%$ and $1.3 \%$ of augmented vertebrae and $3.9 \%$ and $2.2 \%$ of subjects for vertebroplasty ( $\mathrm{n}=2080$ subjects, 3120 vertebrae, 31 studies) and kyphoplasty $(\mathrm{n}=844$ subjects, 1451 vertebrae, 17 studies), respectively. Because pulmonary emboli can cause serious ramifications, asymptomatic emboli were counted as a clinical complication. Pulmonary emboli occurred in $0.6 \%$ and $0.01 \%$ of augmented vertebrae for vertebroplasty and kyphoplasty, respectively, while neurologic complications occurred in $0.6 \%$ and $0.03 \%$ of vertebrae.

\section{New Fracture Rate After Vertebroplasty or Kyphoplasty}

There were 17 vertebroplasty $(\mathrm{n}=933$ subjects) and 12 kyphoplasty ( $\mathrm{n}=766$ subjects) clinical trials that reported new fractures (Figure 5). Of new vertebral fractures using vertebroplasty $(\mathrm{n}=120$ fractures, 12 studies $^{40,42,44,46-49,69-71,94,95}$ ) and kyphoplasty ( $\mathrm{n}=115$ fracture, 9 studies $\left.{ }^{41,44,52,54,56,57,83,85,86}\right), 60 \%$ and $66 \%$, respectively, were adjacent to the augmented vertebra.
Unfortunately, follow-up times were not consistent among studies, and normalization of new fracture rates by assuming a linear trend is invalid, therefore, making direct comparisons among studies of differing time lengths impossible. ${ }^{85}$ It was noted that both Hillmeier ${ }^{56}$ and Kornp ${ }^{58}$ et al commented on the presence of new fractures after kyphoplasty, but actual values were unavailable.

\section{Discussion}

Our review of literature has identified 69 mainly noncontrolled single-group cohort studies. The lack of controls, methodological flaws, and lack of information concerning patient inclusion criteria and fracture definition preclude definitive conclusions. Despite these limitations, we have addressed each question outlined in the introduction and provided a critical evaluation of the current study methodology with future recommendations.

\section{Limitations of This Study}

This review does have limitations. Publication bias may exist by limiting our search to peer-reviewed literature. The inclusion of low-quality studies may be considered a limitation of our study methodology. However, the effect 


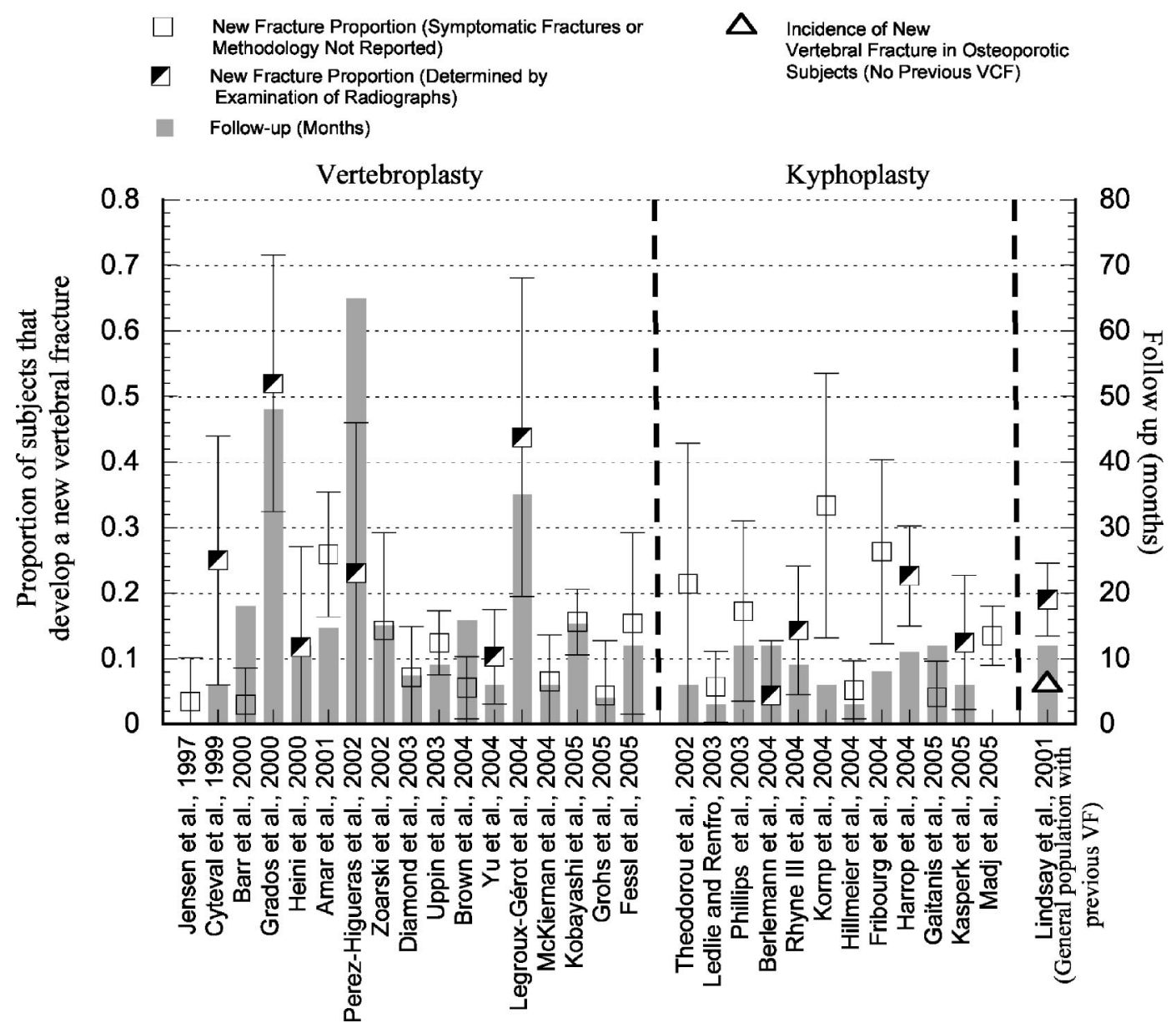

Figure 5. New fracture rate for vertebral augmentations using vertebroplasty and kyphoplasty. The raw reported number of new fractures for the 2 procedures is qualitatively similar. Data from the study by Lindsay et a (104 $^{10}$ has been included, which denotes the incidence rate of a new vertebral fracture during the first year following a vertebral fracture within a general osteoporotic population. New fracture data are presented as the mean $\pm 95 \% \mathrm{Cl}$, while follow-up is presented as the mean.

of methodological quality was assessed, and no significant changes in outcomes were found by removing articles that scored in the bottom $50 \%$. At this juncture, it was thought that confounding factors, patient descriptions, inclusion, and counter-indications were lacking from too many studies to perform a more detailed analysis. Summary means are a reflection of all studies and, as such, can be influenced by study or procedural inclusion criteria. Finally, an article of this scope may be considered premature, that until randomized, blinded clinical trials are performed, the use of summarizing results is questionable. To the contrary, we believe that it is only by assessing what has been performed and evaluating the trends that we can determine the need for future research.

\section{Does Vertebroplasty/Kyphoplasty Reduce Patient Pain? How Does This Compare to Conservative Treatment? Is Pain Reduction Durable Over the Long-term?}

The pain relief experienced by patients appears to be promising for both kyphoplasty and vertebroplasty in the short-term $(<1$ year). The majority of patients have "some pain relief" (Figure 2). Only 2 nonrandomized prospective studies assessed pain relief obtained after the procedure compared with conservative treatment. ${ }^{40,41}$
Augmenting acute painful vertebral fractures, using vertebroplasty, resulted in an immediate (24 hours) decrease in pain scores $(53 \%)$ after surgery. After 6 weeks, both the operated and control groups had a similar clinical outcome (pain score and physical function). In contrast, when assessing the outcome of chronic painful vertebral fractures at 6 months, only the surgical treatment (kyphoplasty) resulted in pain relief compared with controls. It is not known what determines whether a subject will have pain relief. Pain relief is often almost immediate, but in some patients, especially those who have been bedridden for longer periods of time, improvements may be delayed. ${ }^{17,72,105}$ Long-term follow-up results were not as frequently reported. However, it appears that pain relief is durable; little change was noted between postoperative scores and long-term results. ${ }^{4}$

A standard definition of a clinically relevant improvement in pain relief would enhance the comparability, validity, and applicability of the studies (Figure 2). Success should be assessed by the procedure's ability to provide clinically meaningful pain relief for the patient. The effectiveness of the treatment is better reflected in a change in pain grouping (mild pain [1-4], moderate pain 
[5-6], and severe pain [7-10]) than a straight reduction in pain score. ${ }^{106,107}$ It is recommended that a reduction of $33 \%$ of the initial preoperative pain score be adopted as clinically relevant, ${ }^{73,107,108}$ which will eliminate bias associated with pretreatment pain level and ensure consistent, relevant reporting. Furthermore, well-designed studies should be performed to identify patients for whom vertebroplasty or kyphoplasty presents a clear benefit, weighed against the risks associated with the procedure and potential drawbacks of conservative treatment (e.g., loss of BMD, physical condition). ${ }^{8}$

\section{What Are the Complications Associated With the Procedure?}

Leakage of the polymethyl methacrylate is the most common complication and may pose significant physical danger, even in small quantities. ${ }^{17,67,109}$ Leakage of unreacted monomer, or less likely polymethyl methacrylate or venography dye, may produce systemic effects resulting in toxic reaction or allergic effects leading to acute arterial hypotension or fever. ${ }^{34,50,74,75,110}$ Although there is considerable leakage reported during both procedures (Figure 4), the actual leakage rate might have been underreported because of reporting bias or the detection method used. ${ }^{48,111,112}$ Schmidt et al ${ }^{112}$ reported low leakage detection rates and only showed fair interobserver reliability using radiographs. Thus, comparing studies in which leaks were determined by either intraoperative fluoroscopy or postoperative radiograph could be confounded by interobserver effects. It is our opinion that until asymptomatic cement leakage can be disregarded as irrelevant, the best method to monitor cement leakage, CT, should be used to report all leaks, not just those deemed clinically relevant. ${ }^{11,112}$ The information gained through the use of postoperative CT must be balanced against increased patient exposure to radiation and cost.

The majority of clinical complications stem directly from cement leakage (66\% vertebroplasty and $73 \% \mathrm{ky}-$ phoplasty). The vast majority of cement leakage is asymptomatic (96\% vertebroplasty and $89 \%$ kyphoplasty). However, in cases in which cement leakage is immediately clinically asymptomatic, the long-term effect of these "benign" leaks is unknown. Relatively common intradiscal leaks may affect the mechanical loading of either the intravertebral disc or adjacent vertebra. Lin $e t$ $a l^{113}$ reported that $58 \%$ of vertebral bodies adjacent to an intradiscal leak fractured during follow-up compared with only $12 \%$ of vertebral bodies adjacent to augmented vertebrae in which no intradiscal leakage occurred.

Although they are rare, symptomatic leaks may have dramatic consequences, such as paraplegia and death. ${ }^{114-119}$ Cement leakage into the neural foramen is often symptomatic, resulting in neurologic complications. ${ }^{34}$ Neurologic complications were reported in 7 vertebroplasty $10,36,49,68,74,75,102$ and 4 kyphoplasty studies ${ }^{41,55,56,67}$ described as radiculopathy, a worsening of pain or spinal compression or injury. Case reports have documented further major neurologic complica- tions, including paraparesis, spinal claudication, and paraplegia, as a result of vertebroplasty. ${ }^{120,121}$

Cement extravasation into the paravertebral veins may lead to pulmonary embolism or cardiovascular distress. There were 7 vertebroplasty ${ }^{4,17,34,37,42,74,75}$ and 5 kyphoplasty studies ${ }^{8,54,87,88,97}$ that showed pulmonary embolism or cardiac complications. Pulmonary emboli may be a result of cement extravasation or bone marrow and fat particles that are forced out of the vertebra into the circulation. ${ }^{122,123}$ Other instances of pulmonary embolisms, some serious, have been noted in case studies. ${ }^{124,125}$ More pulmonary emboli cases may actually occur than reported because it is not common practice to perform chest radiographs on asymptomatic patients. Chest pain felt after vertebroplasty is often attributed to the procedure but may be caused by embolism. Chest radiographs taken after the procedure may help in the early diagnosis of dyspnea. ${ }^{124,125}$

Higher leakage rates have been reported for singlegroup cohort vertebroplasty studies compared to kyphoplasty studies (Figure 4). The only study that compared kyphoplasty and vertebroplasty using matched groups found little difference in leakage rates $(28 \%$ and $23 \%$ of vertebra had cement leaks for vertebroplasty and kyphoplasty, respectively). ${ }^{44}$ It is noteworthy that although kyphoplasty leaks were all intradiscal, 4 vertebroplasty leaks were into the more critical epidural and segmental vessels regions, although none were symptomatic. ${ }^{44}$ It has been hypothesized that higher injection pressures and lower cement viscosity associated with vertebroplasty may create an environment in which leaks are more likely to occur. ${ }^{52,109}$

However, in a recent study, no significant difference in intravertebral pressure was found between vertebroplasty and kyphoplasty. ${ }^{126}$ It has been postulated that the creation of a cavity may decrease leakage risk. It is interesting to note that those vertebroplasty studies that reduced kyphosis through patient positioning, and often had associated intravertebral clefts, had lower cement extravasation rates than the mean (Figure 4). Kim et $\mathrm{al}^{76}$ noted that during cement filling of vertebrae, which had intravertebral clefts, using vertebroplasty, the IVC was filled before the surrounding trabecular bone in a similar manner to that which occurs during kyphoplasty. Thus, if cement filling is terminated once the cavity is filled, there may be less chance of cement extravasation. ${ }^{66}$

Berlemann et $a l^{52}$ noted that attempting to fill the vertebra rather than just the cavity produced during kyphoplasty resulted in higher leakage rates $(33 \%)$, more similar to leakage rates observed during vertebroplasty. In contrast, Rhyne et $l^{83}$ only filled the cavity produced during kyphoplasty and reported a lower leakage rate $(10 \%)$. Finally, patient inclusion criteria (fracture severity definition, vertebra location, and $\mathrm{BMD}^{77,78}$ ), methodology (leaks determined by CT, radiograph, intraoperatively ${ }^{111,112}$ ), cement parameters (type, percent fill of vertebra $^{52,77}$ ), and operator experience must be similar to compare the safety of the 2 procedures, otherwise one 
runs the risk of determining the effect of the confounding factors rather than the procedures themselves.

\section{Does Vertebroplasty/Kyphoplasty Restore Patient Function?}

Numerous clinically developed but invalidated scales were used to measure physical function. A standardized method would make comparison among studies possible. However, some conclusions can be inferred from the studies reviewed. The relief from pain does seem to allow a large majority of patients to increase their physical function levels. The majority of those patients who had impairments in function before surgery are able to ambulate without assistance after surgery. Improvements in physical function should only be reported for the subset of patients who have preoperative impairments. Inclusion of patients who are normal before surgery will not accurately reflect the efficacy of the intervention to improve physical function because the ratio of impaired and normal subjects will influence the sensitivity.

\section{Does Vertebroplasty/Kyphoplasty Restore Normal Spinal Alignment?}

Both kyphoplasty and vertebroplasty have the ability to reduce the kyphotic angle and restore vertebral height associated with vertebral fractures (Tables 3, 4). Studies assessing the ability of vertebroplasty to restore height identified preoperative dynamic mobility as a good indicator of the potential to restore vertebral height. ${ }^{39,92,93}$ McKiernan et $^{3 l^{39}}$ showed that osteoporotic mobile fractures can achieve some height restoration following vertebroplasty, while nonmobile fractures cannot. Carlier $e t$ $a l^{92}$ reported that the postoperative reduction in kyphosis angle using vertebroplasty can be predicted from the preoperative dynamic mobility, something that remains to be shown for kyphoplasty. Vertebroplasty has no mechanical methods to restore vertebral height and relies on patient positioning or the insertion of bolsters to induce lordosis, to increase the height of the vertebra and reduce the kyphotic angle. ${ }^{45,66,67,76,92,93}$

A majority of the kyphoplasty studies that showed height restoration were performed on vertebrae with acute fractures, which had edema present, or were incompletely healed fractures (Table 3). The presence of these observations increases the probability that the fracture is mobile. Therefore, kyphoplasty may only be successful in restoring height if the fracture is mobile; its ability to restore vertebral height must be assessed relative to the spontaneous correction of the patient's kyphosis through positioning alone. ${ }^{127,128}$ Mobility is mainly associated with the presence of an intravertebral cleft but has been observed in cases in which they are not present. ${ }^{92,129}$ Carlier et al ${ }^{92}$ reported significant differences in height restoration between those subjects in whom an intravertebral cleft was visible and those in whom it was not. Thus, studies that show vertebral height restoration must control for the occurrence of dynamic fracture mobility and intravertebral cleft, the pres- ence of which was only documented for some vertebroplasty studies (Table 4).

Of concern is the high percentage of subjects who do not have any restoration of height following either procedure. One hypothesis is that height restoration is dependent on the age of the fracture. Berlemann et $a l^{52}$ reported that fracture age was one of the predictors of fracture correction, a sentiment that was echoed by Lieberman et al..$^{97}$ However, Phillips et al ${ }^{54}$ found no correlation between the age of fracture and amount of deformity correction. Age of the fracture may not be as critical as its mobility in determining whether a fractured vertebra has the potential to regain height or reduce kyphosis.

Publishing and interpreting increased vertebral height must consider confounding factors (the age, severity, and mobility of the fracture), reporting methodology, and also the accuracy of the measurement method chosen. Study results were presented as a percentage reduction of kyphotic angle or the percentage of height restored, which may favor severe or mild fractures, depending on the calculation method chosen. ${ }^{45}$ The method of reporting restoration of height should be standardized in accordance with the recommendations of McKiernan ${ }^{45}$ and Teng ${ }^{93}$ et al to allow direct interstudy comparisons. Likewise, reporting only the percentage reduction in kyphotic angle is highly sensitive to the initial kyphotic angle. The accuracy of the measurement method must be reported to ensure height restoration exceeds the error. To be $95 \%$ confident that a measured difference in kyphotic wedge angle represents a true change, the required difference has been between $3^{\circ}$ and $11^{\circ} .{ }^{92,127,130,131}$ Intraobserver height measurement SD has been between 0.4 and $1.1 \mathrm{~mm}^{129,132}$

Attention to precision is important in determining the number of subjects for whom the treatment is effective. As is evident from Tables 3 and 4, few studies showed the precision of their methods, and in most, it was not evident if precision was then used in the analysis of the data. Patients whose measured results fall below the determine precision of the measurement method should be considered as nonresponsive. It was only evident in 3 studies if any correction for magnification error was performed (Tables 3, 4). Each radiograph must contain a reference object that allows the vertebral fracture heights to be corrected for, or, alternately, the fracture height can be expressed as a percentage of a reference height (visualized in each radiograph) to negate magnification error. ${ }^{45,93}$ Finally, studies must show both height and kyphosis reduction. As reported by Kasperk et $a l^{41}$ it is entirely possible to have an increase in height and no reduction in kyphosis angle. Likewise, if only middle height is reported, it is possible to have no increase in height but a reduction of kyphosis angle (increase in anterior height only).

The whole objective of vertebral height restoration is to reduce spinal deformity and improve spinal alignment. Kyphotic angle is the angle between the superior and inferior endplates of the fractured vertebra. Unlike 
Cobb angles, which include at least a disc between the measured endplates, this angle is not influenced by body position. ${ }^{67,93}$ As shown in Tables 3 and 4 , at least 5 studies used Cobb angle to determine kyphosis angle reduction. However, it would be useful to have a repeatable and sensitive measurement technique that allowed the overall spinal deformity to be determined.

\section{Does the Incidence of Augmented or Adjacent Vertebral Fracture Increase After Vertebroplasty/Kyphoplasty?}

It is difficult to determine if the incidence rate of new fractures increases after vertebroplasty/kyphoplasty because there is only 1 study $^{41}$ of limited statistical power and short follow-up that compares the new vertebral fracture rate within patients after the procedure compared with a conservative treatment group. Kasperk et $a l^{41}$ determined that there was no significant difference between new fracture rates of patients who underwent kyphoplasty compared to controls (conservative treatment) over a 6 -month period. Grohs et $a l^{44}$ reported a higher incidence of new vertebral fractures for kyphoplasty than vertebroplasty. There were $6(\mathrm{n}=35$ augmented vertebrae) and $1(\mathrm{n}=29$ augmented vertebrae) new fracture(s) that occurred within 4 months for kyphoplasty and vertebroplasty, respectively. Unfortunately, the low study statistical power, lack of fracture definition, short follow-up, and reporting of only symptomatic fractures (rather than radiologically determined new fractures) preclude drawing emphatic conclusions. Additional factors that may confound the results of this study and others include degree of osteoporosis or spinal malalignment, patient physical function level, the quantity of cement injected, and intervertebral disc health.

The occurrence of new fractures after the procedure appears to be nonlinear, with the majority of new fractures occurring within 30 days. $^{71,85}$ Thus, the linear extrapolation of normalized annual fracture incidence rates will result in a faulty estimation. The vertebral fracture incidence rate appears to be higher after the procedure than within the general osteoporotic population that has not had a vertebral fracture develop (cumulative incidence rate of subjects with a mean age of 74 years is $6.6 \%$ ), even among those studies that did not attain an average 1-year follow-up (Figure 5). ${ }^{49,104}$ However, whether there is any difference between fracture rates after the procedure and those within a general osteoporotic population that has had a previous vertebral fracture $\left(19 \%{ }^{104}\right)$ cannot be conclusively ascertained from the data. The presence of a preexisting fracture has been reported to increase one's risk of having a subsequent vertebral fracture develop by 12.6 -fold. ${ }^{133}$ It is noteworthy that two thirds of new fractures reported in studies included in this review were located adjacent to the augmented vertebra.

Grados $^{75}$ and Legroux-Gérot ${ }^{42}$ et al calculated the odds ratio of vertebral fracture in the vicinity of a cemented vertebra to be 2.27 (95\% CI 1.11-4.56) and
3.18 (95\% CI 0.51-19.64), compared with 1.44 (95\% CI $0.82-2.55)$ and 2.14 (95\% CI $0.17-26.31)$ for a vertebral fracture in the vicinity of an uncemented fractured vertebra, respectively. Although this finding may suggest that the risk of fracture is increased adjacent to an augmented vertebra, it may also be caused by the natural progression of osteoporosis. A high incidence rate during the first few months after augmentation, as noted by a few investigators, may be a result of increased patient activity levels after the procedure or possible altered loading, resulting from changes in vertebral geometry or material behavior. ${ }^{71,85,134,135}$ The postoperative care received by the patients was rarely mentioned in the reviewed articles but may play an import role in the new fracture rate. ${ }^{85}$ Patients not instructed in proper body mechanics may be more likely to have a new vertebral fracture.

The incidence rate of new fractures after vertebroplasty/kyphoplasty may be even higher than that reported, depending on the method used to define a new vertebral fracture. New fractures may result in a poor outcome after the procedure but not to the extent that clinical action is required, thereby escaping detection. ${ }^{34}$ Because it is estimated that only $23 \%$ of vertebral fractures are clinical events, long-term follow-up must include new radiologic analysis and not rely on patients returning for reevaluation because of recurrent pain. ${ }^{7,104}$ To ensure that new fractures are properly identified, a standard definition, such as that proposed by Genant, must be used. ${ }^{136}$ Furthermore, fractures that do not require clinical action can have significant long-term consequences. ${ }^{128}$

\section{Does Kyphoplasty Offer a Significant Improvement in Terms of Restoration of Spinal Alignment, Pain Management, and Reduction in Cement Leakage Over Traditional Vertebroplasty?}

At present, to compare kyphoplasty and vertebroplasty, it is necessary to use mainly the results of single group cohort studies, which is far from optimal. Similar results were noted for pain relief when comparing vertebroplasty and kyphoplasty studies. The only study ${ }^{44}$ that compares kyphoplasty and vertebroplasty found that both procedures provided pain relief, but it was more pronounced for kyphoplasty after 2 years $(73 \%$ and $41 \%$ reduction in VAS, respectively), the reason for which was not hypothesized. The body of evidence suggests a high degree of variability in the leakage rate for kyphoplasty and vertebroplasty. Whether the lower leakage rates are a result of patient inclusion criteria, creation of a void or trabecular dam (caused by inflation of the tamp during kyphoplasty), or higher cement viscosity needs to be clarified. ${ }^{48}$ Height restoration is possible using kyphoplasty, although it is not effective for all patients.

However, it has also been noted that similar height restorations may be possible using vertebroplasty. Grohs et $a l^{44}$ compared the height restoration of 2 matched 
subject groups for kyphoplasty and vertebroplasty. They found some height restoration and kyphosis reduction for kyphoplasty, and none for vertebroplasty. However, there was no indication that an attempt was made to reduce the kyphosis for the vertebroplasty group through the use of patient positioning or bolsters, or if kyphosis reduction for patients who underwent kyphoplasty could be achieved by patient positioning alone. It is noteworthy that intravertebral pseudarthrosis was excluded from this investigation. Whether kyphoplasty offers a higher degree of kyphotic angle correction or allows a higher range of fractures to be treated compared with vertebroplasty needs to be ascertained. Long-term new fracture incidence rates appear to be similar for the 2 procedures, but this is based on qualitative examination of the presented data. The problem with stating conclusively that there is or is not a difference between kyphoplasty and vertebroplasty outcomes is the lack of comparative randomized clinical trials.

\section{- Recommendations for the Standardization of Methodology}

Our methodological quality assessment revealed a need for standardized reporting and methodology, randomization, blinding of the patient or the investigator to the treatment received, reporting the variability of the data, and the use of a control group. Although it may be impractical to blind the patient to the procedure, effective study design can ensure that in prospective studies, the investigator is blinded to the patients' treatment allocation. Unblinded study designs may result in differential care bias affecting recorded scores. ${ }^{25}$ Standardization would enhance the comparability, validity, and applicability of the studies. To assess reporting quality, we would encourage investigators to use the checklist presented in this article (Table 1).

We have outlined in each section methodological recommendations to ensure that reporting is relevant and accurate. The methods used to determine the safety and effectiveness of the procedures should include, as a minimum, the following:

- Results should be reported with respect to the fracture pathology.

- Radiologic assessment of fracture severity (using a method such as that proposed by Grigoryan ${ }^{136}$ and Lenchik $^{137}$ et al) and an estimation of the age of the fracture should be included.

- Dynamic fracture mobility (supine lateral radiographs compared with standing radiographs) ${ }^{39}$ and the presence of intravertebral clefts ${ }^{129,100}$ must be noted if reporting height restoration. Height restoration that can be attributed to dynamic mobility must be corrected for if reporting a mechanical method of restoring vertebral height.

- Objective outcome measures should be used to assess a reduction in patient pain. VAS (raw values and the number of patients with clinically relevant reduction in pain) and a disease-specific functional outcome such as the ODI or the Osteoporosis Quality of Life Questionnaire should be included. ${ }^{138}$

- Physical function should be evaluated using 1 of the disease-specific function outcomes listed previously. The improvements should be related to those with preexisting impairments.

- Cement leakage, assessed by CT, should be documented. ${ }^{112}$ Until small leaks can be definitively discounted as having no clinical consequence, all leaks should be reported.

- Kyphosis reduction and height restoration should be noted as per the recommendation of McKiernan et al. ${ }^{45}$ In addition, height restoration relative to the initial height lost should be reported in accordance with the method of Teng et al. ${ }^{93}$ Adjacent normal posterior border height should be replaced with the appropriate reference height on the adjacent vertebra (i.e., anterior, middle, or posterior height). Precision of the radiographic measurement should be noted and accounted for during analysis. Magnification error should be corrected for by standardized radiograph techniques. ${ }^{45,93}$ Vertebral wedge angle should be defined as the angle between the superior and inferior endplates of the fractured vertebra. ${ }^{76}$

- Radiographic assessment of new fractures at 3, 6, and 12 months for all patients should be performed using a fracture definition, such as that proposed by Grigoryan et al. ${ }^{136}$

- All clinical complications should be noted.

The majority of studies included in this review adds to our preliminary knowledge of the procedures, and offer insights into their potential benefits and complications. However, many questions still remain unanswered. They include but are not constrained to: Why does pain relief occur? How can cement leaks be avoided? Are asymptomatic leaks clinically relevant? How do clinical results of vertebroplasty differ from kyphoplasty? What inclusion criteria ensure that pain relief or kyphosis reduction is possible? Can new fractures be prevented (are they a result of the procedures or a natural progression of osteoporosis)? To facilitate the comparison of future studies, the adoption of a standardized reporting method would be highly beneficial. With the assistance of the recommendations proposed, it is now time to proceed to the next step with well-controlled clinical trials.

\section{- Key Points}

- Some pain relief was reported for $92 \%$ and $87 \%$ of kyphoplasty and vertebroplasty procedures, respectively.

- Leakage rates were higher for vertebroplasty $(41 \%)$ than kyphoplasty $(9 \%)$. 
- Height restoration is possible using kyphoplasty and for a subset of patients with mobile fractures using vertebroplasty. However, $34 \%$ and $39 \%$ of kyphoplasty and vertebroplasty (with mobile fracture) procedures, respectively, do not result in any height restoration.

- New fractures of adjacent vertebrae occurred after both procedures. Whether this is caused by altered loading, increased patient activity, or the natural progression of osteoporosis has yet to be determined.

- The adoption of standardized reporting and methodology, and an increase in methodological quality would enhance comparability, validity, and applicability of the studies.

\section{References}

1. Iqbal MM. Osteoporosis: Epidemiology, diagnosis, and treatment. South Med J 2000;93:2-18.

2. Cooper C, Atkinson EJ, Jacobsen SJ, et al. Population-based study of survival after osteoporotic fractures. Am J Epidemiol 1993;137:1001-5.

3. Truumees E, Hilibrand A, Vaccaro AR. Percutaneous vertebral augmentation. Spine J 2004;4:218-29.

4. Zoarski GH, Snow P, Olan WJ, et al. Percutaneous vertebroplasty for osteoporotic compression fractures: Quantitative prospective evaluation of long-term outcomes. J Vasc Interv Radiol 2002;13:139-48.

5. Riggs BL, Melton LJ III. The worldwide problem of osteoporosis: Insights afforded by epidemiology. Bone 1995;17:505S-11S.

6. Silverman SL. The clinical consequences of vertebral compression fracture. Bone 1992;13(suppl 2):S27-31.

7. Cooper C, Atkinson EJ, O'Fallon WM, et al. Incidence of clinically diagnosed vertebral fractures: A population-based study in Rochester, MN, 1985-1989. J Bone Miner Res 1992;7:221-7.

8. Coumans JV, Reinhardt MK, Lieberman IH. Kyphoplasty for vertebral compression fractures: 1-year clinical outcomes from a prospective study. J Neurosurg 2003;99:44-50.

9. Lyles KW, Gold DT, Shipp KM, et al. Association of osteoporotic vertebral compression fractures with impaired functional status. Am J Med 1993;94: 595-601.

10. Evans AJ, Jensen ME, Kip KE, et al. Vertebral compression fractures: Pain reduction and improvement in functional mobility after percutaneous polymethylmethacrylate vertebroplasty retrospective report of 245 cases. Radiology 2003;226:366-72.

11. Kado DM, Duong T, Stone KL, et al. Incident vertebral fractures and mortality in older women: A prospective study. Osteoporos Int 2003;14: 589-94.

12. Galibert P, Deramond H, Rosat P, et al. Preliminary note on the treatment of vertebral angioma by percutaneous acrylic vertebroplasty [in French]. Neurochirurgie 1987;33:166-8.

13. Heini PF, Orler R. Kyphoplasty for treatment of osteoporotic vertebral fractures. Eur Spine J 2004;13:184-92.

14. McGraw JK, Lippert JA, Minkus KD, et al. Prospective evaluation of pain relief in 100 patients undergoing percutaneous vertebroplasty: Results and follow-up. J Vasc Interv Radiol 2002;13:883-6.

15. Gangi A, Guth S, Imbert JP, et al. Percutaneous vertebroplasty: Indications, technique, and results. Radiographics 2003;23:e10.

16. Garfin SR, Yuan HA, Reiley MA. New technologies in spine: Kyphoplasty and vertebroplasty for the treatment of painful osteoporotic compression fractures. Spine 2001;26:1511-5.

17. Moreland DB, Landi MK, Grand W. Vertebroplasty: Techniques to avoid complications. Spine J 2001;1:66-71.

18. Wong W, Riley MA, Garfin S. Vertebroplasty/kyphoplasty. J Womens Imaging 2000;2:117-124.

19. Watts NB, Harris ST, Genant HK. Treatment of painful osteoporotic vertebral fractures with percutaneous vertebroplasty or kyphoplasty. Osteoporos Int 2001;12:429-37.

20. Levine SA, Perin LA, Hayes D, et al. An evidence-based evaluation of percutaneous vertebroplasty. Manag Care 2000;9:56-60.
21. Kallmes DF, Jensen ME. Percutaneous vertebroplasty. Radiology 2003; 229:27-36.

22. Shekelle PG, Woolf SH, Eccles M, et al. Clinical guidelines: Developing guidelines. BMJ 1999;318:593-6.

23. Lieberman I, Reinhardt MK. Vertebroplasty and kyphoplasty for osteolytic vertebral collapse. Clin Orthop Relat Res 2003;415(suppl):S176-86.

24. Downs SH, Black N. The feasibility of creating a checklist for the assessment of the methodological quality both of randomised and nonrandomised studies of health care interventions. J Epidemiol Community Health 1998;52:377-84.

25. MacLehose RR, Reeves BC, Harvey IM, et al. A systematic review of comparisons of effect sizes derived from randomised and non-randomised studies. Health Technol Assess 2000;4:1-154.

26. Slim K, Nini E, Forestier D, et al. Methodological index for nonrandomized studies (minors): Development and validation of a new instrument. ANZ J Surg 2003;73:712-6.

27. Goodman SN, Berlin J, Fletcher SW, et al. Manuscript quality before and after peer review and editing at Annals of Internal Medicine. Ann Intern Med 1994;121:11-21.

28. Liddle J, Williamson M, Irwig L. Methods for Evaluating Research Guideline Evidence. NSW Health Department Sydney, Australia. Available at: http://www.health.nsw.gov.au/pubs/1996/methodeval.html.

29. Altman DG. Systematic reviews of evaluations of prognostic variables. BMJ 2001;323:224-8.

30. Wells G, Shea B, O'Connell D, et al. The Newcastle-Ottawa Scale (NOS) for assessing the quality of nonrandomised studies in meta-analysis. Available at: http://www,ohri.ca/programs/clinical_epidemiology.oxford.htm. Accessed July 12, 2004.

31. van Tulder M, Furlan A, Bombardier C, et al. Updated method guidelines for systematic reviews in the Cochrane collaboration back review group. Spine 2003;28:1290-9.

32. West S, King V, Carey T, et al. Systems to Rate the Strength of Scientific Evidence. Evidence Report/Technology Assessment No. 47. Rockville, MD: Agency for Healthcare Research and Quality; April 2005. AHRQ Publication No. 02-E016.

33. Juni P, Altman DG, Egger M. Systematic reviews in health care: Assessing the quality of controlled clinical trials. BMJ 2001;323:42-6.

34. Amar AP, Larsen DW, Esnaashari N, et al. Percutaneous transpedicular polymethylmethacrylate vertebroplasty for the treatment of spinal compression fractures. Neurosurgery 2001;49:1105-14.

35. Brown DB, Glaiberman CB, Gilula LA, et al. Correlation between preprocedural MRI findings and clinical outcomes in the treatment of chronic symptomatic vertebral compression fractures with percutaneous vertebroplasty. AJR Am J Roentgenol 2005;184:1951-5.

36. Gaughen JR Jr, Jensen ME, Schweickert PA, et al. Relevance of antecedent venography in percutaneous vertebroplasty for the treatment of osteoporotic compression fractures. AJNR Am J Neuroradiol 2002b;23:594-600.

37. Hodler J, Peck D, Gilula LA. Midterm outcome after vertebroplasty: Predictive value of technical and patient-related factors. Radiology 2003;227: 662-8.

38. Lane JM, Johnson CE, Khan SN, et al. Minimally invasive options for the treatment of osteoporotic vertebral compression fractures. Orthop Clin North Am 2002;33:431-8.

39. McKiernan F, Jensen R, Faciszewski T. The dynamic mobility of vertebral compression fractures. J Bone Miner Res 2003;18:24-9.

40. Diamond TH, Champion B, Clark WA. Management of acute osteoporotic vertebral fractures: A nonrandomized trial comparing percutaneous vertebroplasty with conservative therapy. Am J Med 2003;114:257-65.

41. Kasperk C, Hillmeier J, Noldge G, et al. Treatment of painful vertebral fractures by kyphoplasty in patients with primary osteoporosis: A prospective nonrandomized controlled study. J Bone Miner Res 2005;20:604-12.

42. Legroux-Gérot I, Lormeau C, Boutry N, et al. Long-term follow-up of vertebral osteoporotic fractures treated by percutaneous vertebroplasty. Clin Rheumatol 2004;23:310-7.

43. Cortet B, Cotten A, Boutry N, et al. Percutaneous vertebroplasty in the treatment of osteoporotic vertebral compression fractures: An open prospective study. J Rheumatol 1999;26:2222-8.

44. Grohs JG, Matzner M, Trieb K, et al. Minimal invasive stabilization of osteoporotic vertebral fractures: A prospective nonrandomized comparison of vertebroplasty and balloon kyphoplasty. J Spinal Disord Tech 2005;18: $238-42$.

45. McKiernan F, Faciszewski T, Jensen R. Reporting height restoration in vertebral compression fractures. Spine 2003;28:2517-21.

46. Fessl R, Roemer FW, Bohndorf K. Percutaneous vertebroplasty for osteoporotic vertebral compression fractures: Experiences and prospective clinical outcome in 26 consecutive patients with 50 vertebral fractures [in German]. Rofo 2005;177:884-92. 
47. Heini PF, Walchli B, Berlemann U. Percutaneous transpedicular vertebroplasty with PMMA: Operative technique and early results. A prospective study for the treatment of osteoporotic compression fractures. Eur Spine J 2000;9:445-50.

48. McKiernan F, Faciszewski T, Jensen R. Quality of life following vertebroplasty. J Bone Joint Surg Am 2004;86-A:2600-6.

49. Perez-Higueras A, Alvarez L, Rossi RE, et al. Percutaneous vertebroplasty: Long-term clinical and radiological outcome. Neuroradiology 2002;44: 950-4.

50. Nirala AP, Vatsal DK, Husain M, et al. Percutaneous vertebroplasty: An experience of 31 procedures. Neurol India 2003;51:490-2.

51. Gaitanis IN, Hadjipavlou AG, Katonis PG, et al. Balloon kyphoplasty for the treatment of pathological vertebral compressive fractures. Eur Spine J 2005; $14: 250-60$.

52. Berlemann U, Franz T, Orler R, et al. Kyphoplasty for treatment of osteoporotic vertebral fractures: A prospective non-randomized study. Eur Spine J 2004;13:496-501.

53. Crandall D, Slaughter D, Hankins PJ, et al. Acute versus chronic vertebral compression fractures treated with kyphoplasty: Early results. Spine J 2004; $4: 418-24$.

54. Phillips FM, Ho E, Campbell-Hupp M, et al. Early radiographic and clinical results of balloon kyphoplasty for the treatment of osteoporotic vertebral compression fractures. Spine 2003;28:2260-5.

55. Wilhelm K, Stoffel M, Ringel F, et al. Preliminary experience with balloon kyphoplasty for the treatment of painful osteoporotic compression fractures [in German]. Rofo 2003;175:1690-6.

56. Hillmeier J, Grafe I, Da Fonseca K, et al. The evaluation of balloon kyphoplasty for osteoporotic vertebral fractures. An interdisciplinary concept [in German]. Orthopade 2004;33:893-904.

57. Majd ME, Farley S, Holt RT. Preliminary outcomes and efficacy of the first 360 consecutive kyphoplasties for the treatment of painful osteoporotic vertebral compression fractures. Spine J 2005;5:244-55.

58. Kornp M, Ruetten S, Godolias G. Minimal-invasive therapie der funktionell instabilien osteoporotichen Wirbelkorperfraktur mittels Kyphoplastie: Prospektive Vergleichsstudie von 19 operierten und 17 konservative behandelten Patienten. J Miner Stoffwechs 2004;11:13-5.

59. Lane JM, Hong R, Koob J, et al. Kyphoplasty enhances function and structural alignment in multiple myeloma. Clin Orthop Relat Res 2004;426:49-53.

60. Weisskopf M, Herlein S, Birnbaum K, et al. Kyphoplasty-A new minimally invasive treatment for repositioning and stabilising vertebral bodies [in German]. Z Orthop Ihre Grenzgeb 2003;141:406-11.

61. Gaughen JR Jr, Jensen ME, Schweickert PA, et al. Lack of preoperative spinous process tenderness does not affect clinical success of percutaneous vertebroplasty. J Vasc Interv Radiol 2002a;13:1135-8.

62. Gaughen JR Jr, Jensen ME, Schweickert PA, et al. The therapeutic benefit of repeat percutaneous vertebroplasty at previously treated vertebral levels. AJNR Am J Neuroradiol 2002c;23:1657-61.

63. Kallmes DF, Schweickert PA, Marx WF, et al. Vertebroplasty in the midand upper thoracic spine. AJNR Am J Neuroradiol 2002;23:1117-20.

64. Kaufmann TJ, Jensen ME, Schweickert PA, et al. Age of fracture and clinical outcomes of percutaneous vertebroplasty. AJNR Am J Neuroradiol 2001;22:1860-3.

65. Brown DB, Gilula LA, Sehgal M, et al. Treatment of chronic symptomatic vertebral compression fractures with percutaneous vertebroplasty. AJR Am J Roentgenol 2004;182:319-22.

66. Jang JS, Kim DY, Lee SH. Efficacy of percutaneous vertebroplasty in the treatment of intravertebral pseudarthrosis associated with noninfected avascular necrosis of the vertebral body. Spine 2003;28:1588-92.

67. Lee ST, Chen JF. Closed reduction vertebroplasty for the treatment of osteoporotic vertebral compression fractures. Technical note. J Neurosurg 2004;100:392-6.

68. Barr JD, Barr MS, Lemley TJ, et al. Percutaneous vertebroplasty for pain relief and spinal stabilization. Spine 2000;25:923-8.

69. Yu SW, Lee PC, Ma CH, et al. Vertebroplasty for the treatment of osteoporotic compression spinal fracture: Comparison of remedial action at different stages of injury. J Trauma 2004;56:629-32.

70. Kobayashi K, Shimoyama K, Nakamura K, et al. Percutaneous vertebroplasty immediately relieves pain of osteoporotic vertebral compression fractures and prevents prolonged immobilization of patients. Eur Radiol 2005; $15: 360-7$.

71. Uppin AA, Hirsch JA, Centenera LV, et al. Occurrence of new vertebral body fracture after percutaneous vertebroplasty in patients with osteoporosis. Radiology 2003;226:119-24.

72. Peh WC, Gelbart MS, Gilula LA, et al. Percutaneous vertebroplasty: Treatment of painful vertebral compression fractures with intraosseous vacuum phenomena. AJR Am J Roentgenol 2003;180:1411-7.

73. Maynard AS, Jensen ME, Schweickert PA, et al. Value of bone scan imaging in predicting pain relief from percutaneous vertebroplasty in osteoporotic vertebral fractures. AJNR Am J Neuroradiol 2000;21:1807-12.

74. Vasconcelos C, Gailloud P, Beauchamp NJ, et al. Is percutaneous vertebroplasty without pretreatment venography safe? Evaluation of 205 consecutives procedures. AJNR Am J Neuroradiol 2002;23:913-7.

75. Grados F, Depriester C, Cayrolle G, et al. Long-term observations of vertebral osteoporotic fractures treated by percutaneous vertebroplasty. Rheumatology (Oxford) 2000;39:1410-4.

76. Kim DY, Lee SH, Jang JS, et al. Intravertebral vacuum phenomenon in osteoporotic compression fracture: Report of 67 cases with quantitative evaluation of intravertebral instability. J Neurosurg 2004;100:24-31.

77. Ryu KS, Park CK, Kim MC, et al. Dose-dependent epidural leakage of polymethylmethacrylate after percutaneous vertebroplasty in patients with osteoporotic vertebral compression fractures. J Neurosurg 2002;96:56-61.

78. Peh WC, Gilula LA, Peck DD. Percutaneous vertebroplasty for severe osteoporotic vertebral body compression fractures. Radiology 2002;223: 121-6.

79. Kim AK, Jensen ME, Dion JE, et al. Unilateral transpedicular percutaneous vertebroplasty: Initial experience. Radiology 2002;222:737-41.

80. Mousavi P, Roth S, Finkelstein J, et al. Volumetric quantification of cement leakage following percutaneous vertebroplasty in metastatic and osteoporotic vertebrae. J Neurosurg 2003;99:56-9.

81. McGraw JK. Re: Is intraosseous venography a significant safety measure in performance of vertebroplasty? J Vasc Interv Radiol 2002;13:856.

82. Dublin AB, Hartman J, Latchaw RE, et al. The vertebral body fracture in osteoporosis: Restoration of height using percutaneous vertebroplasty. AJNR Am J Neuroradiol 2005;26:489-92.

83. Rhyne A III, Banit D, Laxer E, et al. Kyphoplasty: Report of eighty-two thoracolumbar osteoporotic vertebral fractures. J Orthop Trauma 2004; 18:294-9.

84. Theodorou DJ, Theodorou SJ, Duncan TD, et al. Percutaneous balloon kyphoplasty for the correction of spinal deformity in painful vertebral body compression fractures. Clin Imaging 2002;26:1-5.

85. Fribourg D, Tang C, Sra P, et al. Incidence of subsequent vertebral fracture after kyphoplasty. Spine 2004;29:2270-6.

86. Harrop JS, Prpa B, Reinhardt MK, et al. Primary and secondary osteoporosis' incidence of subsequent vertebral compression fractures after kyphoplasty. Spine 2004;29:2120-5.

87. Darius T, Vanderschot P, Broos P. Balloonkyfoplastiek: Een Nieuwe Behandelingsmethode voor Wevelfracturen bij Osteoporose. Tijdschr voor Geneeskunde 2003;59:1141-51.

88. Ledlie JT, Renfro M. Balloon kyphoplasty: One-year outcomes in vertebral body height restoration, chronic pain, and activity levels. J Neurosurg 2003;98:36-42.

89. Feltes C, Fountas KN, Machinis T, et al. Immediate and early postoperative pain relief after kyphoplasty without significant restoration of vertebral body height in acute osteoporotic vertebral fractures. Neurosurg Focus 2005;18:e5.

90. Ledlie JT, Renfro MB. Decreases in the number and severity of morphometrically defined vertebral deformities after kyphoplasty. Neurosurg Focus 2005;18:e4.

91. O'Brien JP, Sims JT, Evans AJ. Vertebroplasty in patients with severe vertebral compression fractures: A technical report. AJNR Am J Neuroradiol 2000;21:1555-8.

92. Carlier RY, Gordji H, Mompoint DM, et al. Osteoporotic vertebral collapse: Percutaneous vertebroplasty and local kyphosis correction. Radiology 2004;233:891-8.

93. Teng MM, Wei CJ, Wei LC, et al. Kyphosis correction and height restoration effects of percutaneous vertebroplasty. AJNR Am J Neuroradiol 2003; 24:1893-900.

94. Jensen ME, Evans AJ, Mathis JM, et al. Percutaneous polymethylmethacrylate vertebroplasty in the treatment of osteoporotic vertebral body compression fractures: Technical aspects. AJNR Am J Neuroradiol 1997;18: 1897-904.

95. Cyteval C, Sarrabere MP, Roux JO, et al. Acute osteoporotic vertebral collapse: Open study on percutaneous injection of acrylic surgical cement in 20 patients. AJR Am J Roentgenol 1999;173:1685-90.

96. Hiwatashi A, Moritani T, Numaguchi Y, et al. Increase in vertebral body height after vertebroplasty. AJNR Am J Neuroradiol 2003;24:185-9.

97. Lieberman IH, Dudeney S, Reinhardt MK, et al. Initial outcome and efficacy of "kyphoplasty" in the treatment of painful osteoporotic vertebral compression fractures. Spine 2001;26:1631-8.

98. Martin JB, Jean B, Sugiu K, et al. Vertebroplasty: Clinical experience and follow-up results. Bone 1999;25:11S-5S.

99. Phillips FM, Pfeifer BA, Lieberman IH, et al. Minimally invasive treatments of osteoporotic vertebral compression fractures: Vertebroplasty and kyphoplasty. Instr Course Lect 2003;52:559-67. 
100. Lane JI, Maus TP, Wald JT, et al. Intravertebral clefts opacified during vertebroplasty: Pathogenesis, technical implications, and prognostic significance. AJNR Am J Neuroradiol 2002;23:1642-6.

101. Jensen ME, Dion JE. Vertebroplasty relieves osteoporosis pain. Diagn Imaging (San Franc) 1997;19:68, 71-68, 72.

102. McGraw JK, Heatwole EV, Strnad BT, et al. Predictive value of intraosseous venography before percutaneous vertebroplasty. J Vasc Interv Radiol 2002;13:149-53.

103. Grohs JG, Krepler P. Minimal invasive stabilization of osteoporotic vertebral compression fractures. Methods and preinterventional diagnostics. Radiologe 2004;44:254-9.

104. Lindsay R, Silverman SL, Cooper C, et al. Risk of new vertebral fracture in the year following a fracture. JAMA 2001;285:320-3.

105. Fourney DR, Schomer DF, Nader R, et al. Percutaneous vertebroplasty and kyphoplasty for painful vertebral body fractures in cancer patients. J Neurosurg 2003;98:21-30.

106. Bodian CA, Freedman G, Hossain S, et al. The visual analog scale for pain: Clinical significance in postoperative patients. Anesthesiology 2001;95: $1356-61$.

107. Jensen MP, Chen C, Brugger AM. Interpretation of visual analog scale ratings and change scores: A reanalysis of two clinical trials of postoperative pain. J Pain 2003;4:407-14.

108. Farrar JT, Young JP Jr, LaMoreaux L, et al. Clinical importance of changes in chronic pain intensity measured on an 11-point numerical pain rating scale. Pain 2001;94:149-58.

109. Phillips FM, Todd WF, Lieberman I, et al. An in vivo comparison of the potential for extravertebral cement leak after vertebroplasty and kyphoplasty. Spine 2002;27:2173-8.

110. Vasconcelos C, Gailloud P, Martin JB, et al. Transient arterial hypotension induced by polymethylmethacrylate injection during percutaneous vertebroplasty. J Vasc Interv Radiol 2001;12:1001-2.

111. Yeom JS, Kim WJ, Choy WS, et al. Leakage of cement in percutaneous transpedicular vertebroplasty for painful osteoporotic compression fractures. J Bone Joint Surg Br 2003;85:83-9.

112. Schmidt R, Cakir B, Mattes T, et al. Cement leakage during vertebroplasty: An underestimated problem? Eur Spine J 2005;14:466-73.

113. Lin EP, Ekholm S, Hiwatashi A, et al. Vertebroplasty: Cement leakage into the disc increases the risk of new fracture of adjacent vertebral body. AJNR Am J Neuroradiol 2004;25:175-80.

114. Chen HL, Wong CS, Ho ST, et al. A lethal pulmonary embolism during percutaneous vertebroplasty. Anesth Analg 2002;95:1060-2.

115. Childers JC Jr. Cardiovascular collapse and death during vertebroplasty. Radiology 2003;228:902-3.

116. Scroop R, Eskridge J, Britz GW. Paradoxical cerebral arterial embolization of cement during intraoperative vertebroplasty: Case report. AJNR Am J Neuroradiol 2002;23:868-70.

117. Stricker K, Orler R, Yen K, et al. Severe hypercapnia due to pulmonary embolism of polymethylmethacrylate during vertebroplasty. Anesth Analg 2004;98:1184-6.

118. Tozzi P, Abdelmoumene Y, Corno AF, et al. Management of pulmonary embolism during acrylic vertebroplasty. Ann Thorac Surg 2002;74: 1706-8.

119. Yoo KY, Jeong SW, Yoon W, et al. Acute respiratory distress syndrome associated with pulmonary cement embolism following percutaneous vertebroplasty with polymethylmethacrylate. Spine 2004;29: E294-7.

120. Lee BJ, Lee SR, Yoo TY. Paraplegia as a complication of percutaneous vertebroplasty with polymethylmethacrylate: A case report. Spine 2002;27: E419-22.

121. Harrington KD. Major neurological complications following percutaneous vertebroplasty with polymethylmethacrylate: A case report. J Bone Joint Surg Am 2001;83-A:1070-3.

122. Stallmeyer MJ, Zoarski GH, Obuchowski AM. Optimizing patient selection in percutaneous vertebroplasty. J Vasc Interv Radiol 2003;14: 683-96.

123. Aebli N, Krebs J, Davis G, et al. Fat embolism and acute hypotension during vertebroplasty: An experimental study in sheep. Spine 2002;27: $460-6$.

124. Jang JS, Lee SH, Jung SK. Pulmonary embolism of polymethylmethacrylate after percutaneous vertebroplasty: A report of three cases. Spine 2002;27: E416-8.

125. Padovani B, Kasriel O, Brunner P, et al. Pulmonary embolism caused by acrylic cement: A rare complication of percutaneous vertebroplasty. AJNR Am J Neuroradiol 1999;20:375-7.

126. Mathis JM, Ortiz AO, Zoarski GH. Vertebroplasty versus kyphoplasty: A comparison and contrast. AJNR Am J Neuroradiol 2004;25:840-5.

127. Alanay A. Early radiographic and clinical results of balloon kyphoplasty for the treatment of osteoporotic vertebral compression fractures-Point of view. Spine 2003;28:2265-7.

128. Faciszewski T, McKiernan F. Calling all vertebral fractures classification of vertebral compression fractures: A consensus for comparison of treatment and outcome. J Bone Miner Res 2002;17:185-91.

129. McKiernan F, Faciszewski T. Intravertebral clefts in osteoporotic vertebral compression fractures. Arthritis Rheum 2003;48:1414-9.

130. Carman DL, Browne RH, Birch JG. Measurement of scoliosis and kyphosis radiographs. Intraobserver and interobserver variation. J Bone Joint Surg Am 1990;72:328-33.

131. Shea KG, Stevens PM, Nelson M, et al. A comparison of manual versus computer-assisted radiographic measurement. Intraobserver measurement variability for Cobb angles. Spine 1998;23:551-5.

132. Dudeney S, Lieberman IH, Reinhardt MK, et al. Kyphoplasty in the treatment of osteolytic vertebral compression fractures as a result of multiple myeloma. J Clin Oncol 2002;20:2382-7.

133. Melton LJ III, Atkinson EJ, Cooper C, et al. Vertebral fractures predict subsequent fractures. Osteoporos Int 1999;10:214-21.

134. Berlemann U, Ferguson SJ, Nolte LP, et al. Adjacent vertebral failure after vertebroplasty. A biomechanical investigation. J Bone Joint Surg Br 2002; 84:748-52.

135. Polikeit A, Nolte LP, Ferguson SJ. The effect of cement augmentation on the load transfer in an osteoporotic functional spinal unit-Finite-element analysis. Spine 2003;28:991-6.

136. Grigoryan M, Guermazi A, Roemer FW, et al. Recognizing and reporting osteoporotic vertebral fractures. Eur Spine J 2003;12(suppl 2):S104-12.

137. Lenchik L, Rogers LF, Delmas PD, et al. Diagnosis of osteoporotic vertebral fractures: Importance of recognition and description by radiologists. AJR Am J Roentgenol 2004;183:949-58.

138. Measuring quality of life in women with osteoporosis. Osteoporosis Quality of Life Study Group. Osteoporos Int 2005;7:478-87. 